Georgia State University

ScholarWorks @ Georgia State University

Computer Information Systems Faculty

Publications

Department of Computer Information Systems

2013

\title{
The Contingent Effect of Personal IT Innovativeness and IT Self- Efficacy on Innovative Use of Complex IT
}

Wei Wang

Jinan University - China, wangw@jnu.edu.cn

Xixi Li

Tsinghua University, lixx5@sem.tsinghua.edu.cn

J.J. Po-An Hsieh

Georgia State University, jjhsieh@gsu.edu

Follow this and additional works at: https://scholarworks.gsu.edu/cis_facpub

Part of the Management Information Systems Commons

\section{Recommended Citation}

Wang, Wei; Li, Xixi; and Hsieh, J.J. Po-An, "The Contingent Effect of Personal IT Innovativeness and IT Self-Efficacy on Innovative Use of Complex IT" (2013). Computer Information Systems Faculty Publications. 28.

https://scholarworks.gsu.edu/cis_facpub/28

This Article is brought to you for free and open access by the Department of Computer Information Systems at ScholarWorks @ Georgia State University. It has been accepted for inclusion in Computer Information Systems Faculty Publications by an authorized administrator of ScholarWorks @ Georgia State University. For more information, please contact scholarworks@gsu.edu. 


\title{
The Contingent Effect of Personal IT Innovativeness and IT Self- Efficacy on Innovative Use of Complex IT
}

\begin{abstract}
While organizational investment in complex information technologies (IT) keeps growing, these technologies are often applied at a superficial level and fail to attain the promised benefits. To further extract the value potential of complex IT, this study investigates employee users' innovate with IT (IwIT), which is a post-acceptance behavior that refers to individual users' applying IT in novel ways to support their task performance. Drawing on the information systems continuance (ISC) model, we propose a research framework with perceived usefulness (PU) and satisfaction (SAT) as the antecedents of IwIT. We further emphasize the contingent role of personal characteristics and include personal innovativeness with IT (PIIT) and information technology self-efficacy (ITSE) as the moderators of the framework. We validate the model with data from users of two complex ITs: enterprise resource planning (ERP) and business intelligence (BI) technologies. The results suggest that positioning personal factors as moderators significantly increases the explanatory power of the ISC model and offers a more comprehensive understanding about IwIT. Specifically, ITSE positively moderates the effect of PU, and negatively moderates the effect of SAT, on IwIT. The moderating role of PIIT, however, is subject to the specific type of IT of investigation.
\end{abstract}

Keywords: Post-acceptance Use, Innovate with IT, Complex Information Technologies, Personal Innovativeness with IT, IT Self-efficacy, IS Continuance

\section{Introduction}

Organizations are becoming increasingly dependent on information technologies (IT) to enhance their market services and sharpen their competitiveness in order to survive and excel in the global market. As a result, organizations' financial investment in IT has been rising rapidly. Since the 1980s, organizations spend up to 50\% of their new capital investment on IT-related activities (Westland and Clark 2000). The worldwide organizational IT budget has grown steadily in the past decades and surpassed $\$ 3$ trillion in 2007; despite the economic downturn, global IT spending has still increased by nearly $8 \%$, reaching $\$ 3.4$ trillion in 2008 and has continued expanding in 2009 though at a slower rate (Kanaracus 2008, Morgan 2008). Unfortunately, the tremendous investment in IT does not always bring about the benefits promised by vendors and expected by organizations (Jasperson et al. 2005). Organizations that implement modern IT rarely use their IT to its fullest potential or realize the promised returns on investment (Jasperson et al. 2005). This underachievement can be partially attributed to the underutilization of the installed IT (Hsieh and Wang 2007). This study approaches this issue of underutilization by studying the concept of Innovate with IT (IwIT). In this paper, IwIT refers to a user's applying IT in novel ways to support his/her task performance, a high-level usage behavior that surpasses routine and simple ways of use. 
The functional complexity of modern organizational IT, such as enterprise resource planning (ERP), customer relationship management (CRM), supply chain management (SCM), business intelligence (BI), and other IT, provide users with the potential to apply IT at different levels of sophistication (Moore 2002). Employee users can apply a complex IT in a simple and superficial way, sticking to work procedures and requirements as prescribed by managers; alternatively, they can use the complex IT at a higher level by utilizing the technology in creative ways that go beyond routine use (Carlson and Zmud 1999, Chin and Marcolin 2001). These higher-level usage behaviors are valuable because they help improve productivity, generate high value-adding products and services, and ultimately enhance organizations' competencies (Jasperson et al. 2005, Saga and Zmud 1994). IwIT is such a high-level usage behavior that can extract the value potential of implemented IT more fully to support employees' performance (Ahuja and Thatcher 2005).

IwIT is suggested to occur during the post-acceptance stage when users have passed their initial use decisions and become more knowledgeable about the implemented IT (Boudreau and Seligman 2005, Saga and Zmud 1994). Users' familiarity with the IT serves as their knowledge base, which helps them to go beyond the status quo and identify new ways of applying the IT (Sternberg et al. 1997). Thus, we view IwIT as a continued usage behavior that is innovative in nature. Toward this end, the information system continuance (ISC) model (Bhattacherjee 2001) seems to be an ideal lens to understand IwIT as a postacceptance usage behavior. Specifically, the ISC model proposes that users' perceived usefulness (PU) of and satisfaction (SAT) with using IT are two important direct antecedents for post-acceptance usage behaviors.

Meanwhile, some have urged to consider individual factors as boundary conditions for understanding IT use. Modeling personal factors as moderators can help reconcile inconsistent findings among prior literature, increase the explanatory power of the research model, and thus offer a more comprehensive understanding about the phenomenon of interest (Sun and Zhang 2006, Venkatesh et al. 2003). In a more general sense, identifying personal factors as moderators helps researchers further reveal subgroup differences among users and facilitates practitioners' interventions at the post-acceptance stage (Evans and Lepore 1997, Wohlwill and Heft 1987). Therefore, we consider two individual characteristics that matter in the IT use process: personal innovativeness with IT (PIIT) (Agarwal and Prasad 1998) and information technology self-efficacy (ITSE) (Agarwal and Karahanna 2000, Compeau and Higgins 1995a). 
Although PIIT and ITSE have attracted considerable attention in the study of IT acceptance (e.g., intention to use) and general IT use (e.g., time and frequency) (Agarwal 2000, Agarwal and Karahanna 2000, Lewis et al. 2003), their roles for higher-level usage behaviors deserve further elaboration and examination. Indeed, while Agarwal and Prasad (1998) originally proposed PIIT as a moderator that affects the link between individuals' IT perceptions and use, research in this area predominately treats PIIT as a direct predictor of IT use (e.g., Yi et al. 2006). However, the contingent role of PIIT as a moderator between individual cognitions, affects, and usage behaviors, has received little empirical verification. Similarly, most IS studies tend to position ITSE as a direct antecedent of IT use (e.g., Compeau and Higgins 1995b) but discuss its role as an individual boundary condition in explaining IT use less often. As will be explained in the later sections, we believe there are sufficient theoretical reasons to emphasize the influence of PIIT and ITSE as moderators, which will greatly enhance our understanding about IwIT.

Given the above discussions, the main objective of this research is to study users' post-acceptance innovative use of complex IT with a particular focus on understanding the contingent role of personal factors, specifically PIIT and ITSE.

\section{Theory, Research Model and Hypotheses}

\section{Innovate with IT (IwIT)}

Most of the work in creativity research emphasized creativity/innovation as the production of novel and useful ideas by individuals or groups (Amabile et al. 1996). MacKinnon (1962) takes the view that true creativity has three characteristics: (1) it involves a novel idea; (2) the idea must be useful; and (3) the creative idea can be put into action. Meanwhile, Amabile (1988) refers to organizational innovation as the successful development and implementation of creative ideas. This notion of innovation in organizations is in line with McKinnon's view of creativity. In addition, innovation can be illustrated in different forms, such as the outcome of recombining ideas or a proposal challenging current ways of doing things (Mills and Chin 2007). Following this line of reasoning, IwIT embodies the generation and implementation of individual users' creative ideas in the form of IT usage behaviors. Specifically, the concept of IwIT describes a user's applying IT in novel ways to support his/her task performance. Complex IT (e.g., ERP technologies) implemented by modern organizations are usually too sophisticated for organizations and users to fully appreciate and capitalize on its value during the initial acceptance stage (Hsieh and Wang 
2007). When an IT implementation process enters the post-acceptance stage, users' familiarity with the installed IT enables them to partake in innovative use that probably could not be identified at the initial acceptance stage (Ahuja and Thatcher 2005, Jasperson et al. 2005). In this vein, IwIT is considered an effective way to explore the value potential of the complex IT (Ahuja and Thatcher 2005, Jasperson et al. 2005). Hence, understanding the reasons that lead to IwIT is of great importance for organizations to maximize their returns on IT investment.

IwIT in this study evolves from "trying to innovate with IT." Ahuja and Thatcher (2005) define trying to innovate with IT as a user's goal of finding new ways of using existing IT. In addition, there are other concepts similar to IwIT. For example, Nambisan et al. (1999) examined "intention to explore", which stands for a user's willingness and purpose to explore an IT and identify its potential use. Karahanna and Agarwal (2006) conceptualize "intention to explore" as a user's experimentation with an IT and seeking new ways of using it. While these concepts (i.e., trying to innovate with IT and intention to explore) concern users' attempts to innovate with IT and generate ideas (i.e., finding new ways of using IT), IwIT focuses on post-implementation usage behavior that puts new ideas (i.e., new ways of using IT) into action.

Instead of focusing on behavioral intentions or attempts, however, our study examines the IwIT behavior. Indeed, although trying to innovate with IT has been proposed to be an appropriate predictor of IwIT (Ahuja and Thatcher 2005, Ciborra 1991), a proxy may not guarantee the occurrence of the target behavior due to unexpected impediments (Ahuja and Thatcher 2005, Nah et al. 2004). Emerging literature also suggests that an intention or attempt to use an IT may not be the best predictor of usage behavior in the post-adoptive context (e.g., Jasperson et al. 2005, Kim and Malhotra 2005). Following this line of reasoning, this study chooses to examine the behavior (i.e., IwIT) rather than behavioral intentions or attempts. Note that while there are also studies that examine innovative IT use at the organizational level and draw on macro level theoretical lenses (e.g., Li et al. 2006), our unit of analysis and, hence, theoretical focus center on individual-level behavior.

Conceptually speaking, IwIT consists of two core properties: continuity and innovativeness. Continuity represents users' continuance in using IT after their initial use, whereas innovativeness concerns the novelty in how users apply the IT. Figure 1 illustrates our research model with IwIT specified as the dependent variable. In the following sections, we resort to the ISC model and the contingent effects of personal factors to account for IwIT. 
Insert Figure 1 here

\section{The IS Continuance Model}

In general, there are two lines of continuance research. The first regards continuance as an extension of initial acceptance and employs IT acceptance perspectives to study continuance behavior (e.g. Bagozzi $e t$ al. 1992, DeSanctis and Poole 1994, Taylor and Todd 1995). More recently, some have argued that initial acceptance does not guarantee continued use because continuance is not a natural extension of initial acceptance (Bhattacherjee 2001). To address this concern, drawing on expectation-confirmation theory (Oliver 1980, Oliver and Shapiro 1993), Bhattacherjee (2001) proposes the IS continuance (ISC) model as an alternative lens for understanding continuance behavior. His study is one of the earliest to conceptualize and test a theoretical model of IS continuance, which takes into account the distinctions between acceptance and continued use. Since then, ISC has been widely accepted and employed for studying continuance behaviors.

Since IwIT is supposed to occur during the post-acceptance stage (Ahuja and Thatcher 2005, Saga and Zmud 1994) and is characterized by the continuity element, the ISC model seems to be an ideal theoretical lens for understanding IwIT. Grounded in expectation-confirmation theory, the ISC model proposes that confirmation of expectation (COE) influences users' perceived usefulness (PU) and satisfaction (SAT) with regard to the target IT; PU affects SAT, and PU and SAT jointly determine users' continuance intentions (Bhattacherjee 2001). According to the ISC model, PU is an individual cognitive perception that captures individuals' rational evaluation of the external benefits derived from using an IT (Bhattacherjee 2001, Davis et al. 1989). SAT, on the other hand, is essentially an emotional state and represents individuals' affective feelings toward using the IT (Bhattacherjee 2001). IwIT, which is partially a continued usage behavior, is associated with PU and SAT. Note that COE in the ISC model is omitted in this research because it only indirectly affects continued use through PU and SAT and is thus less relevant to our research interest.

\section{Direct Effects of ISC Factors: PU and SAT}

PU refers to a user's perception that using an IT will enhance his/her performance within an organization, which captures the instrumentality of IT use (Davis et al. 1989). PU has long been identified as the key factor affecting individual IT use (Venkatesh et al. 2003). Here, we address PU's importance in leading to 
IwIT at the post-acceptance stage. At the post-acceptance stage, PU is formed mostly through users' firsthand experience (Bhattacherjee 2001). For users who want to find new ways of using IT to support their task performance, utilitarian evaluation of IT use represents a logical and rationale assessment regarding whether further devotion of users' time and efforts may pay off. In this vein, it is reasonable to expect that when individuals perceive that using an IT will enhance their performance, they will be willing to spend more time and effort in experimenting with the IT so as to find innovative ways to use it (Karahanna and Agarwal 2006, Li and Hsieh 2007). Therefore, we propose:

H1. Perceived Usefulness will be positively related to IwIT.

Different from PU, SAT is individual affective emotional state derived from prior interaction with an IT. SAT reflects users' overall affective feelings about their usage experience (Bhattacherjee 2001). In the post-acceptance stage, users are more willing to continuously engage in using an IT if they are satisfied with their direct experience with it. Some have viewed SAT as a post-acceptance attitudinal affect that indicates whether users are identified with an IT in use (Bhattacherjee 2001, Bhattacherjee and Premkumar 2004). If employee users are satisfied with their direct interactions with the IT, they are more likely to identify with it, embrace it, and attempt to use it at a higher level like IwIT. Thus, we believe:

H2. Satisfaction will be positively related to IwIT.

\section{The Contingent Role of Individual Characteristics: PIIT and ITSE}

Some have encouraged to model individual factors as moderators in studying IS use (Agarwal and Prasad 1998, Venkatesh et al. 2003). As argued by Sun and Zhang (2006), incorporating individual factors as moderators could enhance the low explanatory power of existing research models and help reconcile inconsistent findings among existing literature. Moderating effects usually offer a more comprehensive picture of connections among constructs than simple linear relationships. Given that scholars have identified PIIT and ITSE as the two most relevant individual factors for IT use (Agarwal 2000, Gallivan et al. 2005). We believe that these two factors also play important roles as moderators for IwIT.

An individual is regarded as "innovative" when he/she adopts an innovation early on (Rogers 2003). PIIT refers to the degree to which an individual is willing to try out a new IT (Agarwal and Prasad 1998). PIIT characterizes individual risk-taking propensity in the IT use process (Agarwal and Prasad 1998, Rogers 2003, Thatcher and Perrewe 2002). In this study, we propose that PIIT moderates the relationships 
between the ISC factors (i.e., PU and SAT) and IwIT.

As discussed earlier, IwIT is closely associated with risk, uncertainty, and imprecision (Ahuja and Thatcher 2005, Nambisan et al. 1999). While the utilitarian organizational rewards (i.e., PU) could be instrumental in stimulating IwIT, such a motivational effect can easily be hampered by unexpected risks and failures during the innovation process of attaining IwIT. Meanwhile, the notion of PIIT characterizes one's risk-taking propensity in the face of an IT (Agarwal and Prasad 1998, Rogers 2003) and tolerance of uncertainty in the IT use process (Bommer and Jalajas 1999, Thatcher and Perrewe 2002). Individuals with a higher level of PIIT are more sensitive to, and thus would collect more novel information that serves as the inspiration for attaining creative behaviors (Hirschman 1980). With this backdrop, it is reasonable to argue that users' willingness to take risks, endurance of uncertainty, and inclination to identify and collect novel information brought about by a high level of PIIT will facilitate those who are instrumentally motivated toward identifying new ways of applying the IT. Thus, when provided with encouraging rewards for using the IT, individuals with a higher level of PIIT, as compared to those who are less innovative, tend to be more willing to take initiatives to experiment with the IT and find new ways of using it. On the contrary, even if users perceive using an IT as constructive for performance enhancement, a low level of PIIT would hinder users from taking initiatives to seek innovative use. Thus,

H3a. PIIT will moderate the relationship between Perceived Usefulness and IwIT such that the relationship will be stronger for users with high PIIT than for users with low PIIT.

Similarly, a high level of PIIT could amplify the influence of SAT on IwIT. According to Rogers (2003), innovative individuals (i.e., those with high PIIT) usually have a positive view of change. Thus, already satisfied with prior IT use, users with a high level of PIIT would be even more encouraged to challenge themselves by generating and testing new ideas for using the IT. Conversely, holding the same level of satisfaction, users with a lower level of PIIT are likely to be more conservative and unwilling to engage in risk-taking behaviors, thereby impeding the innovation process toward IwIT (Agarwal and Prasad 1998, Amabile 1988, Rogers 2003). The positive effect of SAT on IwIT would be consequently hampered by a low level of PIIT.

H3b. PIIT will moderate the relationship between Satisfaction and IwIT such that the relationship will be stronger for users with high PIIT than for users with low PIIT.

Self-efficacy represents an individual's beliefs regarding his/her ability to perform a particular course 
of action or behavior (Bandura 1997). Self-efficacious individuals tend to be more committed to pursuing goals (Latham et al. 2000), more perseverant in the face of obstacles (Schaefers et al. 1997), and more active in information searching (Wood et al. 1999). Established on the generic self-efficacy concept, ITSE is defined as an individual's judgment of his/her ability to use an IT (Compeau and Higgins 1995a, 1995b). ITSE focuses on one's belief regarding his/her personal skills and abilities and, therefore, represents an internal locus of control in performing IT use. ITSE, as a context-specific form of self-efficacy, is also supposed to be associated with users' commitment, perseverance, and information seeking behavior regarding IT use. Next, we discuss the contingent effect of ITSE for PU and SAT.

Complex IT usually poses a high knowledge cognitive burden that challenges users (Gattiker and Goodhue 2005). Considering IwIT as an activity to be accomplished by users, ITSE can be considered as an internal cognitive resource, with which users are able to apply an IT effectively (Hsieh et al. forthcoming). When individuals are motivated toward engaging in a certain behavior, their perceptions whether relevant resources are available or not would positively affect their behavioral accomplishments (Hu et al. 2007). Prior literature has also indicated that the effects of external motivation and personal capabilities are complementary in influencing human behaviors (c.f., Atkinson 1964, Porter and Lawler 1968), which may also be the case for PU and ITSE when considering IwIT. Specifically, for individuals who are motivated to use an IT because they believe using it will enhance their performance, having a high level of self-efficacy in using the IT will enable them to commit themselves toward exploring the IT further, engaging in more information searching that will help to expand their knowledge with regard to the IT, and enduring the necessary trial-and-error processes for attaining IwIT. On the other hand, having the same level of PU, individuals with low self-efficacy for operating the IT may attain a lower level of IwIT because they would behave in a rather passive manner (Luthans and Youssef 2007) and would lack the needed commitment, initiative, and endurance for indentifying new ways of using the IT (Krueger and Dickson 1993, 1994). The above discussions lead to the following hypothesis:

H4a. ITSE will moderate the relationship between Perceived Usefulness and IwIT such that the relationship will be stronger for users with high ITSE than for users with low ITSE.

Different from the previous three moderation hypotheses, we propose that ITSE negatively moderates the impact of SAT on IwIT. Quite a few empirical studies have found that the influence of affective feelings derived from organizational support has a stronger behavioral impact on those who are less self- 
efficacious than those who are more self-efficacious (Martocchio and Dulebohn 1994, Martocchio and Webster 1992, Saks 1995, Vanyeperten 1998). Specifically, individuals with a low level of self-efficacy tend to believe that they do not have adequate competencies to cope with challenges or to carry out their responsibilities for their job. In this case, the feelings derived from the positive affect toward organizational support has an important psychological function that makes these individuals believe their organization supports them as they perform work-related tasks, thereby leading to positive behavioral consequences (Vanyeperten 1998). However, for individuals with a higher level of self-efficacy, the affective feelings about organizational support play a less important role, since they are confident enough about their own abilities (Vanyeperten 1998).

Following this line of reasoning, we argue that there is a negative interaction effect between SAT and ITSE on IwIT. As discussed above, ITSE represents individuals' belief in their capabilities for using a target IT, and SAT indicates whether employee users are satisfied with the IT supported by the organization. As argued in H1, higher SAT leads to higher IwIT. This positive affect (i.e., SAT) likely comforts users and helps them overcome their fears of failure and their anxiety as they search for novel ways of using the IT. Such a supportive feeling would be useful for stimulating high-level usage behaviors like IwIT, particularly for those who lack confidence in their own abilities for using the IT. However, for users with a high level of ITSE who already have strong confidence in their own competencies, this psychological affect (i.e., SAT) would be less effective for driving their IwIT. As such, we believe:

H4b. ITSE will moderate the relationship between Satisfaction and IwIT such that the relationship will be stronger for users with low ITSE than for users with high ITSE.

\section{Research Methodology}

To enhance the generalizability of our research, we conducted two empirical studies in two different IT contexts. We chose Enterprise Resource Planning (ERP) technology and Business Intelligence (BI) technology as the target complex IT for Study 1 and Study 2, respectively. These two types of complex IT are commonly adopted by modern organizations and usually come with a complex array of functionalities that permit users to apply the IT in novel fashions (Hsieh and Wang 2007, Wang and Hsieh 2006). Next, we describe the two research sites, measurement scales, and survey procedures.

\section{Data Site and Sample}

Study 1

Page 9 of 39 
Study 1 was conducted in a large organization in Southern China. ERP technology is the target complex IT for this investigation. Conceptually speaking, ERP technology is an enterprise-wide IT that encompasses various business processes and incorporates an organization's internal and external operations (Boudreau and Seligman 2005). ERP technology is a completely distinct class of IT application and different from conventional technologies that are functionally simple (Gattiker and Goodhue 2005).

To capture individuals' IwIT, we confine the scope of this study to the post-acceptance stage. The target firm had implemented and applied the ERP technology for more than two years by the time of data collection. As suggested by prior literature, a complex IT is generally not utilized to its fullest potential eighteen to twenty-four months after its implementation (Boudreau 2003, Hsieh and Wang 2007); thus, the two-year implementation span seems appropriate for capturing users' IwIT in the post-acceptance stage.

Insert Table 1 here

Similar to most ERP implementation projects, employees were required to use the IT in the target firm (Nah et al. 2004, Pozzebon 2002). Nevertheless, they were not mandated to find new ways of applying the IT. During an in-depth interview, the CIO confirmed that the knowledge workers who participated in our survey had the discretion to modify their current applications of the IT and for proposing new uses of the ERP technology. In other words, these knowledge workers were able to make decisions about and devote efforts to IwIT, but were not required to do so. Thus, IwIT is essentially a voluntary behavior for these subjects. These employee users of the ERP technology are therefore suitable subjects for this study. With the endorsement from the top management, we distributed 220 copies of questionnaires to randomly sampled knowledge workers who used the ERP technology and received 200 responses (see Table 1 for sample demographics).

\section{Study 2}

Study 2 was conducted in a large telecom service company in Eastern China. The target complex IT of investigation is BI technology. BI technology is data-driven decision-support technology that integrates functions like data gathering, data storage, data analysis, and knowledge management (Negash and Gray 2008). The main purpose of BI technology is to provide input for decision-making processes within organizations (Negash and Gray 2008). BI technology usually analyzes large volumes of data, which are typically drawn or refined from a data warehouse or data mart. The generated results are used for firms' 
strategic decision-making, daily management, and operations. Like ERP technology, the sophisticated analytical functions in BI technology, ranging from simple reporting to slice-and-dice, drill down, answering ad hoc queries, real-time analysis, and forecasting (Negash and Gray 2008), allow huge room for users' innovative usage behaviors.

By the time of data collection, the BI technology had also been implemented for two years in the selected company, thus also being considered as within the post-acceptance stage. We distributed the questionnaires to 217 randomly sampled users of the technology and received 193 responses. The subjects are knowledge workers who use the technology to analyze data, generate business-related reports, and make/ propose strategic decisions. Table 2 summarizes this sample's characteristics.

Insert Table 2 here

\section{Measurement Scale}

We used multi-item Likert scales, ranging from 1 (strongly disagree) to 7 (strongly agree), to measure the variables in the research model. All of the scales are all adapted from prior studies for the contexts of investigation (See Appendix A-1 and A-2). For IwIT, we adapted the original two items of trying to innovate with IT (Ahuja and Thatcher 2005) and focused on employees' innovative usage behavior. Meanwhile, to ensure that employees' IwIT behavior is associated with job-related purposes, we explicitly denoted the linkage between novel use and task performance. For the ISC factors, three items of PU were adapted from Davis (1989), and three items of SAT were adapted from Bhattacherjee (2001). For the individual factors, three items of PIIT were assessed using the scales from Agarwal and Prasad (1998), and three items of ITSE were adapted from Taylor and Todd (1995) and Compeau and Higgins (1995b).

\section{Control Variable}

To rule out possible alternative explanations, we controlled for basic demographic factors, such as gender, education, age, tenure, and prior use experience. These factors were all selected based on prior IS literature (Agarwal and Prasad 1999, Venkatesh et al. 2003).

\section{Procedures}

Survey procedures were similar across the two studies. First, both studies assumed a cross-sectional research design with data collection from employee users of the target IT. Next, we followed standardized translation and back-translation procedures for questionnaire development (Brislin et al. 1973). Four 
professional translators took care of the translation and back-translation process with two responsible for translating the measures from English to Chinese and the other two from Chinese to English. We then conducted a pilot study to assess construct validity and reliability by distributing the instrument to 18 ERP users in a third company that is different from the ones in Studies 1 and 2. The results exhibited acceptable measurement properties. Finally, we conducted the large-scale survey in the two companies for Studies 1 and 2 .

\section{Data Analysis and Results}

We selected Partial Least Squares (PLS) for data analysis. PLS has widely been applied in the IS field due to its minimal demands on data distribution and residual distributions (Chin 1998). SmartPLS was chosen as the analytical software (Ringle et al. 2005). We first evaluated the psychometric properties of the measurement model and then tested the structural model and the associated hypotheses.

\section{Reliability and Validity Assessment}

Measurement properties are usually evaluated in terms of internal consistency, convergent validity, and discriminant validity. Internal consistency and convergent validity are ensured when the values of Cronbach's alpha and composite reliability are higher than 0.707 (Nunnally 1994) and when the values of average value extracted (AVE) are above 0.5 (Fornell and Larcker 1981). Discriminant validity is supported when AVE of a variable is higher than its squared correlations with other variables and when the item loadings on its primary variable are higher than the loadings on other variables (Chin 1998, Gefen and Straub 2005).

Study 1

Table 3 displays the descriptive statistics and the values of Cronbach's alpha, composite reliability, and AVE. Table 4 displays the items loadings and cross-loadings. By referring to the criteria stated above, we concluded that the five variables in our research model display good psychometric properties for Study 1. Insert Table $3 \&$ Table 4 here

\section{Study 2}

Table 5 and Table 6 report the relevant statistics for assessing the variables' internal consistency, convergent validity, and discriminant validity for Study 2. Again, we obtained good psychometric properties for the five variables in our research model. 
Insert Table $5 \&$ Table 6 here

\section{Hypotheses Testing}

After establishing the measurement model, we proceeded to test the structural model. We followed a stepwise procedure for hypotheses testing. In step 1, we included all of the control variables and examined their impact on the dependent variable, IwIT. In step 2, we added the two independent variables, PU and SAT, and the two moderators, PIIT and ITSE. In Step 3, we incorporated the theorized interaction terms following (1) the approach suggested by Chin et al. (2003) and (2) the approach by Goodhue et al. (2007). Both approaches arrived at almost identical results.

Study 1

Table 7 illustrates the results from Study 1. In Model 1, two of the five control variables displayed significant impacts on IwIT (education: $\beta=-0.205$, $\mathrm{p}<0.01$; use time: $\beta=0.130, \mathrm{p}<0.05$ ). Model 1 explained $6.1 \%$ of the variance in IwIT. In Model 2, PU and SAT both significantly affected IwIT (PU: $\beta=0.320$, $\mathrm{p}<0.01$; SAT: $\beta=0.162, \mathrm{p}<0.05)$; H1 and H2 are thus supported for Study 1 . On the other hand, while PIIT had a salient direct effect on IwIT $(\beta=0.162, p<0.01)$, ITSE did not. As compared to Model 1 , the explained variance of IwIT in Model 2 increased by $24.7 \%$, thereby reaching $30.8 \%$.

In Model 3, we examined the interaction effects. We found that 1) PIIT positively moderated the impact of SAT on IwIT (SAT*PIIT: $\beta=0.204, \mathrm{p}<0.01$ ), 2) ITSE positively moderated the effect of PU (PU*ITSE: $\beta=0.230, p<0.01)$ and negatively moderated the effect of SAT (SAT*ITSE: $\beta=-0.209, \mathrm{p}<0.01)$ on IwIT, and 3) PIIT showed no significant moderating effect on the path from PU to IwIT. Hence, H3b, $\mathrm{H} 4 \mathrm{a}$, and H4b were supported in Study 1, but H3a was not. The three significant interaction effects collectively explained an additional $5.7 \%$ of the variance in IwIT, thereby raising the explained variance in IwIT to $36.5 \%$ from $30.8 \%$ in Model 2. This represents an 18.6\% enhancement from Model 2 to Model 3 in terms of explanatory power (i.e., $\left(\mathrm{R}^{2}\right.$ of Model $3-\mathrm{R}^{2}$ of Model 2$) / \mathrm{R}^{2}$ of Model $2=18.6 \%$ ).

Insert Table 7 here

\section{Study 2}

Table 8 illustrates the PLS results of Study 2. In Model 1, gender is the only control variable that had a significant impact on IwIT (gender: $\beta=0.113, p<0.05$ ). The explained variance of IwIT in Model 1 was 3.3\%. In Model 2, both PU and SAT had significant impacts on IwIT (PU: $\beta=0.222, p<0.01 ;$ SAT: $\beta=0.196$, 
$\mathrm{p}<0.01$ ). Consistent with Study 1, H1 and H2 were also supported in Study 2. While PIIT exerted a salient direct effect on IwIT $(\beta=0.146, p<0.05)$, ITSE had a moderate impact on IwIT $(\beta=0.109, p<0.1)$. As compared to Model 1, the explained variance of IwIT in Model 2 increased by $23.8 \%$, thereby reaching $27.1 \%$.

In Model 3, we found that 1) PIIT positively moderated the impact of PU on IwIT (PU*PIIT: $\beta=0.110$, $\mathrm{p}<0.1$ ), 2) ITSE positively moderated the impact of PU (PU*ITSE: $\beta=0.143, p<0.05$ ) and negatively moderated the impact of SAT (SAT*ITSE: $\beta=-0.221, \mathrm{p}<0.01$ ) on IwIT, and 3) PIIT showed no significant moderating effect on the path from SAT to IwIT. Therefore, H3a, H4a, and H4b are supported in Study 2, while $\mathrm{H} 3 \mathrm{~b}$ is not. The three significant interaction effects collectively explained an additional $5.5 \%$ of the variance in IwIT, thereby raising the explained variance in IwIT to $32.6 \%$ from $27.1 \%$ in Model 2 . This represents an $20.3 \%$ enhancement from Model 2 to Model 3 in terms of explanatory power (i.e., $\left(\mathrm{R}^{2}\right.$ of Model $3-\mathrm{R}^{2}$ of Model 2$) / \mathrm{R}^{2}$ of Model $2=20.3 \%$ ).

Insert Table 8 here

\section{Additional Analysis}

We conducted a series of tests to assess the robustness of the results in the two studies. We reanalyzed the data using partial analysis, group analysis, and the Winsorized method. All of these robustness checks yielded consistent findings with the results reported above (Appendix B).

\section{Discussions}

Table 9 summarizes the findings. All of the six hypotheses are either fully or partially supported. H1 and $\mathrm{H} 2$ are confirmed in both studies, thus supporting the appropriateness of applying the ISC model to explain IwIT as a continuance usage behavior in the post-acceptance stage. Personal factors, such as PIIT and ITSE, further contribute to our attempts to explain IwIT in a more nuanced manner, thereby enhancing the explanatory power of the ISC model. For PIIT, $\mathrm{H} 3 \mathrm{a}$ and $\mathrm{H} 3 \mathrm{~b}$ are partially supported. H3a was supported in Study 2, while H3b was valid in Study 1. The results still suggest that PIIT moderates the impacts of PU and SAT on IwIT, although this effect could be context dependent. For ITSE, H4a and H4b are confirmed in both studies. ITSE positively moderates the impact of PU on IwIT and negatively moderates the impact of SAT on IwIT. We discuss these results in the following section.

Insert Table 9 here 


\section{The Explanatory Power of the ISC Factors: PU and SAT}

Our study extends the applicability of the ISC model to explain IwIT, a representative high-level usage behavior that occurs in the post-acceptance stage. The ISC model suggests that users' continued use of a given IT during the post-acceptance stage is directly driven by their perceptions regarding the instrumentality of using the IT and their satisfaction with prior IT use. In our study, PU and SAT explained a significant amount of variance in IwIT. The strong relationship between PU and IwIT suggests that users' IwIT can be motivated effectively by their utilitarian outcome evaluations (Davis 1989). In addition, SAT's strong effect on IwIT suggests that users' novel use is also influenced by their affective feelings derived from prior usage experience. To conclude, the ISC model serves as an effective theoretical lens for understanding IwIT as a post-acceptance usage behavior.

\section{The Contingent Role of Personal Factors: PIIT and ITSE}

In addition to the ISC model, we incorporated two important individual characteristics to further explain IwIT. The two individual characteristics, PIIT and ITSE, are treated as boundary conditions for the ISC framework. The results confirmed our expectations that PIIT and ITSE are salient contingent factors that can enhance the explanatory power of the ISC model. To achieve a more nuanced understanding about the identified interaction effects, we plotted the interaction diagrams as shown in Figures 3, 4, 5, 6, 7 and 8. We also conducted simple slope tests (Aiken and West 1991) to evaluate if a path coefficient is significantly different from zero. A none-significant path is marked with "n.s." in the figures.

PIIT

According to our results, PIIT positively moderated the link between PU and IwIT in Study 2 (H3a Figure 3) and the link between SAT and IwIT in Study 1 (H3b - Figure 4). As depicted in Figure 2, when perceiving IT use as constructive for performance enhancement, users with a high level of PIIT tend to display more IwIT than those with a low level of PIIT. Indeed, innovative users' risk-taking propensity, tolerance of uncertainty, and tendency to find innovative information can help those who are motivated towards attaining IwIT (Agarwal and Prasad 1998, Rogers 2003). However, this hypothesis is confirmed only in Study 2 but not in Study 1. Figure 3 indicates that users with a high level of PIIT are more sensitive toward their satisfaction with prior IT use and are encouraged by such satisfactory experience for attaining IwIT. By contrast, users with a low level of PIIT tend to be indifferent toward IwIT even if they are satisfied with their prior IT use. Nevertheless, the moderation effect of PIIT on the path from SAT to IwIT 
is validated in Study 1 but not in Study 2.

Insert Figure $2 \& 3$ here

One possible explanation for the inconsistent findings with regard to the above two moderating effects across the two studies may lie in the differences between the two technologies under investigation. While ERP and BI technologies are popular complex IT, they still differ in certain aspects. For instance, ERP technology is generally more operation-driven and more prepared for users' work applications; thus employee users may find innovative use to be a low priority. BI technology is more flexible and analyticaloriented, thus making innovative use a higher priority for employees' IT use. In other words, IwIT is more utilitarian or instrumental for users of BI technology than for users of EPR technology. Thus, for BI users, it is the effect of their utilitarian evaluation (PU) on IwIT, rather than the effect of affective feelings (SAT) on IwIT, that is more sensitive to users' PIIT. By contrast, for ERP users, it is the effect of their satisfactory affect on IwIT that is more sensitive to individuals' PIIT.

ITSE

As confirmed in both studies, ITSE positively moderated the impact of PU on IwIT (H4a - Figures 5 and 7), while it negatively moderated the impact of SAT on IwIT (H4b - Figures 6 and 8). Figures 4 and 6 display similar patterns regarding the moderation effect of ITSE on the link between PU and IwIT. Specifically, an enhancement in PU can constructively induce more IwIT for users with a higher level of ITSE but not for users with a lower level of ITSE. The instrumental effect of users' outcome evaluations toward and self-efficacy in using an IT are complementary in nature for driving innovative use of complex IT.

Figures 5 and 7 also illustrate convergent findings: the impact of SAT on IwIT was more salient for less confident users but not functional for confident users. For users who feel unconfident about their own abilities for using an IT, their affective feelings about the IT supported by the organization play a meaningful role in driving their innovative use. For users with sufficient confidence in their abilities to operate the IT, this affect is of little importance. Thus, the effects of user satisfaction and ITSE on IwIT are substitutive in nature.

Insert Figure 4, 5, 6 \& 7 here

Finally, regarding the control variables, we found that use time had a positive impact on and education had a negative impact on IwIT in Study 1, suggesting that users with a lower education level and longer usage 
experience are more likely to innovate with IT in the ERP context. On the one hand, more usage experience enables individuals to gain more familiarity with the technology, thereby facilitating innovative IT use (Saga and Zmud 1994). On the other hand, users with higher education levels may assume higher administrative roles and hence have less overall engagement with the technology. Meanwhile, we found that gender had a positive impact on IwIT in Study 2, suggesting that male users are more likely to innovate with BI technology. We also found that subjects in Study 1 tend to be older, have lower education, and consist of more females than subject in Study 2. The above differences regarding individuals' demographic profiles and the impacts of the control variables across the two studies could also possibly cause the differences in the moderation effects of PIIT, an issues that deserves further investigation.

\section{LIMITATIONS}

Although we have rigorous evidences to prove the robustness and credibility of our research findings, some limitations still need to be addressed. To begin with, the two empirical studies both adopted a crosssectional research design. In reality, since the variables in our study rarely remain unchanged over time, the cross-sectional research design may not fully capture the dynamics in the IwIT phenomenon. A longitudinal study tracing individuals' IwIT behavior may provide a richer understanding of behavioral patterns, the critical factors related to IwIT, and how these are shaped over time.

In addition, our data were self-reported by IT users. This single data source and cross-sectional research design may possibly cause common method bias (CMB). We took the following actions to mitigate and control for the potential threat of CMB. First, we carefully designed the survey instrument and counterbalanced the order of measurement items (Podsakoff et al. 2003). Second, we performed the Harmon one-factor test for each data set (Podsakoff and Organ 1986) after data collection. A factor analysis combining all of the variables showed no sign of a single factor accounting for the majority of covariance. Third, following the recommendation of Podsakoff et al. (2003) and the analytical procedures used by Liang et al. (2007), we further assessed the magnitude of CMB in our data (Appendices C-1 and C-2). All of these evidences indicate that CMB is not a significant concern in the two studies.

Moreover, although this study focuses primarily on IwIT, there are other types of post-adoptive usage behaviors that deserve further attention (e.g., adaptive use, extended use, and integrative use) (Hsieh and Wang 2007, Saga and Zmud 1994, Sun and Zhang 2008). When choosing the usage behaviors for investigation, researchers should carefully consider the technology being used. For technologies that are 
more malleable and allow for creating new applications, innovative use may be the proper focus. Our focus on IwIT, we believe, is consistent with the embedded functional complexity of ERP and BI technologies.

\section{Contributions and Implications}

\section{For Research}

Our study enriches the understanding of one representative innovative usage behavior at the postacceptance stage: IwIT. IwIT refers to a user's applying IT in novel ways to support his/her work. Prior IS literature commonly examined generic usage behaviors, like duration of use (Venkatesh et al. 2003) and frequency of use (van der Heijden 2004). The generic use of IT is indeed important for organizations; however, such a simple conceptualization of IT use provide little insight for researchers to understand the dynamics in the post-acceptance stage and for practitioners to extract the value potentials of implemented IT to a fuller extent (Saga and Zmud 1994). In this paper, IwIT is proposed as an innovative usage behavior to address the problem of IT underutilization (Jasperson et al. 2005).

According to prior literature, IwIT is likely to occur during the post-acceptance stage (Jasperson et al. 2005, Saga and Zmud 1994). As such, we apply the ISC model to understand IwIT (Bhattacherjee 2001). Our results confirmed the continuance nature of IwIT: the two salient determinants for the general continuance of IT use (i.e., PU and SAT) had significant impacts on IwIT. The salient relationship between PU and IwIT represents the rational mechanism that leads to individuals' innovative behavior with complex IT. Users carefully assess the instrumentality of an IT before devoting more time and effort to identify new ways of applying the IT. Meanwhile, the link between SAT and IwIT suggests that there is an affective mechanism that also leads to IwIT. That is, whether an individual will engage in IwIT will be partially subject to his/her affective feelings derived from his/her prior interactions with the IT. Thus, the rational and the affective mechanisms jointly inform the continuance aspect of IwIT.

Although the ISC model is a good starting point for understanding IwIT as a post-acceptance usage behavior, our results reveal that the explanatory power of the ISC model could be improved by incorporating two personal characteristics as contingency factors: PIIT and ITSE. The revealed moderation relationships extend our knowledge on the contingent role played by individual characteristics for explaining IwIT. Prior literature has mostly considered individual factors as direct determinants of IT use (e.g., Agarwal 2000, Agarwal and Prasad 1999, Compeau and Higgins 1995b, Gallivan et al. 2005, Yi et al. 2006); however, few studies have focused on their moderation effects. By incorporating PIIT and ITSE 
as moderators of the ISC factors, the proposed research model effectively increases the explanatory power of the ISC model and provides more comprehensive insights into the investigated phenomenon (Sun and Zhang 2006). These findings endorse the appropriateness and benefits of our moderation approach and have important implications for future research. When studying IT usage behaviors in various implementation stages, researchers need to pay more attention to the contingent roles of individual characteristics and examine their effects as moderators.

Our research findings also shed light on several important directions for future research. First, given its innovative nature, IwIT is supportive in enhancing employee users' job performance in a way that was not recognized or expected prior to the implementation of the IT (Jasperson et al. 2005). An important research agenda is to further investigate the behavioral outcomes of IwIT and determine if it brings about concrete benefits to users and organizations. In addition, we believe that post-acceptance usage behaviors could also be understood through other theoretical lenses, such as learning and politics (Jasperson et al. 2005). Future studies can examine if these or other theoretical lenses could be applied to further our understanding of novel usage behaviors at the post-acceptance stage. With regard to the contingent role of individual characteristics, interested scholars should consider other personal factors, such as personality (Devaraj et al. 2008), that may be important boundary conditions for understanding IT use. Moreover, the specific type of IT of investigation could be another factor for consideration. Our research findings suggest that the moderation effects of PIIT vary according to different technology settings. Future research should examine the proposed framework in other IT settings and investigate the IT's role in affecting the moderation effects of individual factors. Finally, while innovative use can occur at the individual level, it can also take place at the organizational level (Li et al. 2006), which demands theoretical explanation from a level that is totally different from this study. Therefore, interested scholars should seek to understand the interrelationship between innovative use at different theoretical levels.

\section{For Practice}

Our study also has important implications to the practice. Novel IT use has the potential to resolve problems related to IT underutilization of IT and the low returns of organizational IT investment (Jasperson et al. 2005, Wang and Hsieh 2006). Instead of buying new IT, attaining higher level usage behaviors of and extracting more value from already installed IT could be a worthwhile effort with a much lower incremental financial investment. Thus, we call for practitioners' attention toward the innovative 
usage behaviors that emerge during the post-acceptance stage of IT implementation process.

Employee users' novel use of complex IT could be fostered by nurturing their rational assessment of and affective responses to the IT. The strong association between PU and IwIT suggests that employee users in an organizational context are fairly pragmatic. Their motivations toward using IT, to a large extent, rely on their instrumental evaluation of the IT. Thus, employees are more likely to explore and experiment with an IT when they believe that it provides considerable or desirable utilities for their performance. Meanwhile, managers should strive to ensure that employees have satisfying experiences when using the IT. Satisfaction concerns users' actual experience versus their expectations (Oliver 1980). Thus, while managers should deliver appropriate IT experiences, they should also focus on setting up proper expectations among users in order to avoid situations of low expectation or over-promising but underdelivery.

In addition, managers should be aware of the contingent effects of individual differences on IwIT. Individuals' innovativeness with regard to IT (i.e., PIIT) could be considered a valuable resource to cope with potential problems throughout the IT implementation process. However, it is important to note that PIIT is a rather stable individual trait (Agarwal and Prasad 1998). Thus, rather than trying to manipulate PIIT, managers should focus on identifying individuals who are innovative with IT through their recruitment and selection processes. To capitalize on the contingent effect of PIIT, managers should also take the IT context into consideration. In particular, for operation-oriented complex IT such as ERP technology, the affective feelings with regard to the IT would be stronger for individuals with higher PIIT; whereas for analytical driven complex IT, like BI technology, users' utilitarian perceptions have stronger impacts for those with higher PIIT.

Managers should also pay attention to the moderating role of ITSE. Specifically, ITSE positively moderates the impact of PU on IwIT, while it negatively moderates the impact of SAT on IwIT. This suggests that managers can benefit by distinguishing between individuals with different levels of ITSE and leverage on this individual difference tactically to meet their desired outcomes. For individuals with a higher level of ITSE, managers can emphasize enhancing their usefulness perceptions about an IT. However, for individuals with a low level of ITSE, managers can focus on increasing their satisfaction affect toward the IT. 
Appendix A-1: Sample Measurement Items and Sources (Study 1)

\begin{tabular}{|c|c|c|}
\hline Construct & Measure & Sources \\
\hline Satisfaction & $\begin{array}{l}\text { SAT1. I am very satisfied with the ERP technology usage. } \\
\text { SAT2. I am very pleased with the ERP technology usage. } \\
\text { SAT3. I am very content with the ERP technology usage. }\end{array}$ & $\begin{array}{l}\text { Bhattacherjee } \\
\text { (2001) }\end{array}$ \\
\hline $\begin{array}{l}\text { Perceived } \\
\text { Usefulness }\end{array}$ & $\begin{array}{l}\text { PU1. Using the ERP technology improves my job performance. } \\
\text { PU2. Using the ERP technology in my job increases my productivity. } \\
\text { PU3. Using the ERP technology enhances my effectiveness in my job. }\end{array}$ & Davis (1989) \\
\hline $\begin{array}{l}\text { Personal IT } \\
\text { Innovativeness }\end{array}$ & $\begin{array}{l}\text { PIIT1: If I heard about a new information technology, I would look for } \\
\text { ways to experiment with it. } \\
\text { PIIT2: Among my peers, I am usually the first to try out new } \\
\text { information technologies. } \\
\text { PIIT3: I like to experiment with new information technologies. }\end{array}$ & $\begin{array}{l}\text { Agarwal and } \\
\text { Prasad (1998) }\end{array}$ \\
\hline $\begin{array}{l}\text { Information } \\
\text { Technology } \\
\text { Self-Efficacy }\end{array}$ & $\begin{array}{l}\text { I could complete the job using the ERP technology, } \\
\text { ISSE1: if there was no one around to tell me what to do as I go. } \\
\text { ISSE2: if I had seen someone else using it before trying it myself. } \\
\text { ISSE3: if I could call someone for help if I got stuck. }\end{array}$ & $\begin{array}{l}\text { Compeau and } \\
\text { Higgins (1995b) } \\
\text { Taylor and Todd } \\
(1995)\end{array}$ \\
\hline $\begin{array}{l}\text { Innovate with } \\
\text { IT }\end{array}$ & $\begin{array}{l}\text { IwIT1: I have found new uses of this ERP technology to enhance my } \\
\text { productivity. } \\
\text { IwIT2: I have used this ERP technology in novel ways to help my work. }\end{array}$ & $\begin{array}{l}\text { Ahuja and } \\
\text { Thatcher (2005) }\end{array}$ \\
\hline
\end{tabular}

Appendix A-2: Sample Measurement Items and Sources (Study 2)

\begin{tabular}{|l|l|l|}
\hline \multicolumn{1}{|c|}{ Construct } & \multicolumn{1}{|c|}{ Measure } & \multicolumn{1}{|c|}{ Sources } \\
\hline Satisfaction & $\begin{array}{l}\text { SAT1. I am very satisfied with the BI technology usage. } \\
\text { SAT2. I am very pleased with the BI technology usage. } \\
\text { SAT3. I am very content with the BI technology usage. }\end{array}$ & $\begin{array}{l}\text { Bhattacherjee } \\
\text { (2001) }\end{array}$ \\
\hline $\begin{array}{l}\text { Perceived } \\
\text { Usefulness }\end{array}$ & $\begin{array}{l}\text { PU1. Using the BI technology improves my job performance. } \\
\text { PU2. Using the BI technology in my job increases my productivity. } \\
\text { PU3. Using the BI technology enhances my effectiveness in my job. }\end{array}$ & Davis (1989) \\
\hline $\begin{array}{l}\text { Personal IT } \\
\text { Innovativeness }\end{array}$ & $\begin{array}{l}\text { PIIT1: If I heard about a new information technology, I would look for } \\
\text { ways to experiment with it. } \\
\text { PIIT2: Among my peers, I am usually the first to try out new } \\
\text { information technologies. }\end{array}$ & $\begin{array}{l}\text { Agarwal and } \\
\text { Prasad (1998) }\end{array}$ \\
\hline $\begin{array}{l}\text { Information } \\
\text { Technology } \\
\text { Self-Efficacy }\end{array}$ & $\begin{array}{l}\text { I could complete the job using the BI technology, } \\
\text { ISSE1: if there was no one around to tell me what to do as I go. } \\
\text { ISSE2: if I had seen someone else using it before trying it myself. } \\
\text { ISSE3: if I could call someone for help if I got stuck. }\end{array}$ & $\begin{array}{l}\text { Compeau and } \\
\text { Tiggins (1995b) } \\
\text { (1995) }\end{array}$ \\
\hline $\begin{array}{l}\text { Innovate with } \\
\text { IT }\end{array}$ & $\begin{array}{l}\text { IwIT1: I have found new uses of this BI technology to enhance my } \\
\text { productivity. }\end{array}$ & $\begin{array}{l}\text { Ahuja and } \\
\text { Thatcher (2005) }\end{array}$ \\
\hline
\end{tabular}


IwIT2: I have used this BI technology in novel ways to help my work.

Page 22 of 39 


\section{Appendix B-1: Robustness Checks for Study 1}

We conducted further tests to assess the robustness of the moderation role of the two individual factors, PIIT and ITSE. Results are reported in Table B-1. Columns (2)-(5) report the results of the partial models. These alternative specifications have no material impacts on the results of the hypothesis testing.

Columns (6)-(9) assessed the moderating effect using another complementary method, group analysis. Following Cohen et al. (2003), we split the sample into high and low PIIT groups (PIIT > mean or PIIT < mean) and into high and low ITSE groups (ITSE > mean or ITSE < mean). The results of these columns are consistent with those in column (1), indicating that a) the path coefficients of PU were significantly different between the high and low PIIT groups and b) the path coefficients of SAT were significantly different between the high and low ITSE groups as well as between the high and low ITSE groups.

Finally, Carte and Russell (2003) note that a Likert-scale dependent variable may not sufficiently capture the variation introduced by an interaction term, because the multiplicative interaction may potentially have high variation. To address this concern, we winsorized each of the four interactions (PU $\times$ PIIT, PU $\times$ ITSE, SAT $\times$ PIIT SAT $\times$ ITSE) at the 5\% level, which decreased the variations of the interaction terms (Kaplan \& Zingales, 1997). Specifically, we used the $5^{\text {th }}$ percentile to replace all values below it and the $95^{\text {th }}$ percentile to replace all values above it. As seen in column (10), this test yielded qualitatively unchanged results.

\section{Appendix B-2: Robustness Checks for Study 2}

We conducted further tests to assess the robustness of the moderation role of the two individual factors, PIIT and ITSE. The results are reported in Table B-2. Columns (2)-(5) report the results of the partial models. These alternative specifications have no material impacts on the results of hypothesis testing.

Columns (6)-(9) assessed the moderating effect using another complementary method: group analysis. Following Cohen et al. (2003), we split the sample into high and low PIIT groups (PIIT > mean or PIIT < mean) and into high and low ITSE groups (ITSE > mean or ITSE < mean). The results of these columns are consistent with those in column (1), indicating that a) the path coefficients of PU were significantly different between the high and low PIIT groups and b) the path coefficients of SAT were significantly different between the high and low ITSE groups as well as between the high and low ITSE Groups.

Finally, Carte and Russell (2003) note that a Likert-scale dependent variable may not sufficiently capture the variation introduced by an interaction term, because the multiplicative interaction may potentially have high variation. To address this concern, we winsorized each of the four interactions (PUXPIIT, PU $\times$ ITSE, SAT $\times$ PIIT SAT $\times$ ITSE) at the 5\% level, which decreased the variations of the interaction terms (Kaplan \& Zingales, 1997). Specifically, we used the $5^{\text {th }}$ percentile to replace all values below it and the $95^{\text {th }}$ percentile to replace all values above it. As seen in column (10), this test yielded qualitatively unchanged results. 
TABLE B-1. Robustness checks for study 1.

\begin{tabular}{|c|c|c|c|c|c|c|c|c|c|c|}
\hline \multirow{2}{*}{$\mathrm{DV}=$ Innovate with $\mathrm{IT}^{\dagger}$} & \multirow{2}{*}{$\begin{array}{c}\text { Base } \\
\text { Model }\end{array}$} & \multicolumn{4}{|c|}{$\begin{array}{c}\text { Partial } \\
\text { Models }\end{array}$} & \multicolumn{4}{|c|}{$\begin{array}{c}\text { Group } \\
\text { Analysis }\end{array}$} & \multirow{2}{*}{\begin{tabular}{|c|}
$\begin{array}{l}\text { Winsorized } \\
\text { Interactions }\end{array}$ \\
$(10)$
\end{tabular}} \\
\hline & & (2) & (3) & (4) & $(5)$ & (6) & $(7)$ & $(8)$ & $(9)$ & \\
\hline$R^{2}$ & $36.5 \%$ & $31.3 \%$ & $32.8 \%$ & $33.0 \%$ & $33.1 \%$ & $36.9 \%$ & $26.5 \%$ & $40.5 \%$ & $36.6 \%$ & $37.8 \%$ \\
\hline \multicolumn{11}{|l|}{ IS Continuance Factors } \\
\hline PU & $0.298 * *$ & $0.321 * *$ & $0.320 * *$ & $0.312 * *$ & $0.320 * *$ & & & & & $0.280 * *$ \\
\hline SAT & $0.190 *$ & $0.169 *$ & $0.169 *$ & $0.171 *$ & $0.162 *$ & & & & & $0.183 *$ \\
\hline$P U$, if PIIT $>$ median & & & & & & $0.249 *$ & & & & \\
\hline$S A T$, if PIIT $>$ median & & & & & & $0.336 * *$ & & & & \\
\hline$P U$, if PIIT $<$ median & & & & & & & $0.348 * *$ & & & \\
\hline$S A T$, if PIIT $<$ median & & & & & & & -0.017 & & & \\
\hline$P U$, if ITSE $>$ median & & & & & & & & $0.637 * *$ & & \\
\hline$S A T$, if ITSE $>$ median & & & & & & & & 0.015 & & \\
\hline$P U$, if ITSE $<$ median & & & & & & & & & 0.134 & \\
\hline$S A T$, if ITSE $<$ median & & & & & & & & & $0.360 * *$ & \\
\hline \multicolumn{11}{|l|}{ Personal Factor } \\
\hline PIIT & $0.157 * *$ & $0.159 * *$ & $0.170 * *$ & $0.156 * *$ & $0.161 * *$ & 0.112 & $0.245^{* *}$ & 0.037 & 0.123 & $0.140^{*}$ \\
\hline ITSE & -0.016 & -0.031 & -0.020 & -0.013 & -0.029 & 0.009 & -0.092 & $0.203 * *$ & 0.079 & -0.004 \\
\hline \multicolumn{11}{|l|}{ Interactions } \\
\hline$P I I T \times P U$ & -0.113 & 0.073 & & & & & & & & -0.114 \\
\hline$P I I T \times S A T$ & $0.204 * *$ & & $0.147 * *$ & & & & & & & $0.224 * *$ \\
\hline$I T S E \times P U$ & $0.203 * *$ & & & $0.178 *$ & & & & & & $0.218 * *$ \\
\hline$I T S E \times S A T$ & $-0.209 * *$ & & & & $-0.184 *$ & & & & & $-0.216 * *$ \\
\hline
\end{tabular}

Every model includes control variables.

For convenience, column (0) presents the results shown in the original model in Table 5.

$* \mathrm{p}<0.05, * * \mathrm{p}<0.01$ 
TABLE B-2. Robustness checks for study 2.

\begin{tabular}{|c|c|c|c|c|c|c|c|c|c|c|}
\hline \multirow{2}{*}{$\mathrm{DV}=$ Innovate with $\mathrm{IT}^{\dagger}$} & \multirow{2}{*}{$\begin{array}{c}\text { Base } \\
\text { Model } \\
(1)\end{array}$} & \multicolumn{4}{|c|}{$\begin{array}{l}\text { Partial } \\
\text { Models }\end{array}$} & \multicolumn{4}{|c|}{$\begin{array}{c}\text { Group } \\
\text { Analysis }\end{array}$} & \multirow{2}{*}{\begin{tabular}{|c|}
$\begin{array}{l}\text { Winsorized } \\
\text { Interactions }\end{array}$ \\
$(10)$
\end{tabular}} \\
\hline & & (2) & (3) & (4) & (5) & (6) & $(7)$ & $(8)$ & (9) & \\
\hline$R^{2}$ & $32.6 \%$ & $28.9 \%$ & $27.3 \%$ & $28.3 \%$ & $28.8 \%$ & $23.6 \%$ & $27.6 \%$ & $35.7 \%$ & $20.0 \%$ & $29.5 \%$ \\
\hline \multicolumn{11}{|l|}{ IS Continuance Factors } \\
\hline PU & $0.258 * *$ & $0.209 * *$ & $0.216 * *$ & $0.206 * *$ & $0.265 * *$ & & & & & $0.253 * *$ \\
\hline SAT & $0.133 *$ & $0.175 * *$ & $0.194 * *$ & $0.200 * *$ & $0.164 * *$ & & & & & $0.157 *$ \\
\hline$P U$, if PIIT $>$ median & & & & & & $0.317 * *$ & & & & \\
\hline$S A T$, if PIIT $>$ median & & & & & & $0.151 *$ & & & & \\
\hline$P U$, if PIIT $<$ median & & & & & & & $0.107^{*}$ & & & \\
\hline$S A T$, if PIIT < median & & & & & & & $0.232 * *$ & & & \\
\hline$P U$, if ITSE $>$ median & & & & & & & & $0.510 * *$ & & \\
\hline$S A T$, if ITSE > median & & & & & & & & 0.017 & & \\
\hline$P U$, if ITSE $<$ median & & & & & & & & & 0.028 & \\
\hline$S A T$, if ITSE $<$ median & & & & & & & & & $0.261 * *$ & \\
\hline \multicolumn{11}{|l|}{ Personal Factor } \\
\hline PIIT & $0.177 * *$ & $0.169 * *$ & $0.151 *$ & $0.153 *$ & $0.147^{*}$ & 0.025 & $0.112 *$ & $0.153 * *$ & $0.146 *$ & $0.167 * *$ \\
\hline ITSE & 0.051 & $0.137 *$ & $0.110^{+}$ & $0.110^{+}$ & 0.057 & $0.107 *$ & $0.166 * *$ & 0.012 & $0.133^{*}$ & $0.111^{+}$ \\
\hline \multicolumn{11}{|l|}{ Interactions } \\
\hline$P I I T \times P U$ & $0.110^{+}$ & $0.136^{*}$ & & & & & & & & $0.103^{+}$ \\
\hline$P I I T \times S A T$ & 0.004 & & 0.042 & & & & & & & 0.038 \\
\hline$I T S E \times P U$ & $0.143^{*}$ & & & $0.111^{*}$ & & & & & & $0.106^{+}$ \\
\hline$I T S E \times S A T$ & $-0.221 * *$ & & & & $-0.141^{*}$ & & & & & $-0.107 *$ \\
\hline
\end{tabular}

Every model includes control variables.

For convenience, column (0) presents the results shown in the original model in Table 5.

$* \mathrm{p}<0.05, * * \mathrm{p}<0.01$ 
APPENDIX C-1. Common method bias analysis of study 1.

\begin{tabular}{|l|c|c|c|c|}
\hline \multicolumn{1}{|c|}{ Item } & $\begin{array}{c}\text { Substantive Factor } \\
\text { Loading (R1) }\end{array}$ & $\mathbf{R 1}^{\mathbf{2}}$ & $\begin{array}{c}\text { Common Method } \\
\text { Factor Loading (R2) }\end{array}$ & $\mathbf{R 2}^{2}$ \\
\hline PU (item_1) & $0.768^{* *}$ & 0.591 & $0.210^{* *}$ & 0.044 \\
\hline PU (item_2) & $0.873^{* *}$ & 0.762 & $-0.093^{*}$ & 0.009 \\
\hline PU (item_3) & $0.895^{* *}$ & 0.800 & -0.078 & 0.006 \\
\hline SAT (item_1) & $0.959^{* *}$ & 0.920 & 0.002 & 0.000 \\
\hline SAT (item_2) & $0.940^{* *}$ & 0.883 & -0.005 & 0.000 \\
\hline SAT (item_3) & $0.972^{* *}$ & 0.944 & 0.003 & 0.000 \\
\hline PIIT (item_1) & $0.932^{* *}$ & 0.868 & 0.093 & 0.009 \\
\hline PIIT (item_2) & $0.773^{* *}$ & 0.597 & $-0.148{ }^{* *}$ & 0.022 \\
\hline PIIT (item_3) & $0.780^{* *}$ & 0.608 & 0.047 & 0.002 \\
\hline ITSE (item_1) & $0.846^{* *}$ & 0.715 & 0.055 & 0.003 \\
\hline ITSE (item_2) & $0.895^{* *}$ & 0.800 & -0.027 & 0.001 \\
\hline ITSE (item_3) & $0.947^{* *}$ & 0.897 & -0.025 & 0.001 \\
\hline IwIT (item_1) & $0.940^{* *}$ & 0.883 & -0.050 & 0.002 \\
\hline IwIT (item_2) & $0.952^{* *}$ & 0.907 & 0.049 & 0.002 \\
\hline PU * PIIT (item_1) & $1.000^{* *}$ & 1.000 & 0.000 & 0.000 \\
\hline SAT * PIIT (item_1) & $1.000^{* *}$ & 1.000 & 0.000 & 0.000 \\
\hline PU * ITSE (item_1) & $1.000^{* *}$ & 1.000 & 0.000 & 0.000 \\
\hline SAT * ITSE (item_1) & $1.000^{* *}$ & 1.000 & 0.000 & 0.000 \\
\hline \hline Average & $0.91^{*}$ & 0.843 & 0.002 & 0.006 \\
\hline
\end{tabular}

$* \mathrm{p}<0.05, * * \mathrm{p}<0.01$

APPENDIX C-2. Common method bias analysis of study 2.

\begin{tabular}{|l|c|c|c|c|}
\hline \multicolumn{1}{|c|}{ Item } & $\begin{array}{c}\text { Substantive Factor } \\
\text { Loading (R1) }\end{array}$ & $\mathbf{R 1}^{2}$ & $\begin{array}{c}\text { Common Method } \\
\text { Factor Loading (R2) }\end{array}$ & $\mathbf{R 2}^{2}$ \\
\hline PU (item_1) & $0.975^{* *}$ & 0.951 & -0.070 & 0.005 \\
\hline PU (item_2) & $0.862^{* *}$ & 0.743 & $0.088^{* *}$ & 0.008 \\
\hline PU (item_3) & $0.929^{* *}$ & 0.862 & -0.020 & 0.000 \\
\hline SAT (item_1) & $0.907^{* *}$ & 0.822 & -0.008 & 0.000 \\
\hline SAT (item_2) & $0.909^{* *}$ & 0.826 & 0.059 & 0.003 \\
\hline SAT (item_3) & $0.949^{* *}$ & 0.900 & -0.054 & 0.003 \\
\hline PIIT (item_1) & $0.859^{* *}$ & 0.738 & 0.039 & 0.002 \\
\hline PIIT (item_2) & $0.886^{* *}$ & 0.784 & 0.011 & 0.000 \\
\hline PIIT (item_3) & $0.908^{* *}$ & 0.824 & -0.050 & 0.003 \\
\hline ITSE (item_1) & $0.760^{* *}$ & 0.577 & $0.192^{* *}$ & 0.037 \\
\hline ITSE (item_2) & $0.890^{* *}$ & 0.792 & 0.042 & 0.002 \\
\hline ITSE (item_3) & $0.880^{* *}$ & 0.775 & $-0.339^{* *}$ & 0.115 \\
\hline IwIT (item_1) & $0.919^{* *}$ & 0.845 & 0.031 & 0.001 \\
\hline IwIT (item_2) & $0.957^{* *}$ & 0.915 & -0.031 & 0.001 \\
\hline PU * PIIT (item_1) & $1.000^{* *}$ & 1.000 & 0.000 & 0.000 \\
\hline SAT * PIIT (item_1) & $1.000^{* *}$ & 1.000 & 0.000 & 0.000 \\
\hline PU * ITSE (item_1) & $1.000^{* *}$ & 1.000 & 0.000 & 0.000 \\
\hline SAT * ITSE (item_1) & $1.000^{* *}$ & 1.000 & 0.000 & 0.000 \\
\hline \hline Average & 0.922 & 0.853 & -0.006 & 0.010 \\
\hline
\end{tabular}

$* \mathrm{p}<0.05, * * \mathrm{p}<0.01$ 


\section{References}

AGARWAL, R., 2000, Individual acceptance of information technologies. In Framing the Domains of IT Management: Projecting the Future...Through the Past, R.W. Zmud (Ed.), pp. 85-104 (Cincinnati, OH: Pinnaflex Educational Resources).

AGARWAL, R. and KARAHANNA, E., 2000, Time flies when you're having fun: cognitive absorption and beliefs about information technology usage. MIS Quarterly, 24, pp. 665-695.

AGARWAL, R. and PRASAD, J., 1998, A conceptual and operational definition of personal innovativeness in the domain of information technology. Information Systems Research, 9, pp. 204-215.

AGARWAL, R. and PRASAD, J., 1999, Are individual differences germane to the acceptance of new information technologies. Decision Sciences, 30, pp. 361-391.

AHUJA, M. K. and THATCHER, J.B., 2005, Moving beyond intentions and toward the theory of trying: Effects of work environment and gender on post-adoption information technology use. MIS Quarterly, 29, pp. 427459.

AIKEN, L.S. and WEST, S.G., 1991, Multiple Regression: Testing and Interpreting Interactions (Newbury Park, CA: Sage).

AMABILE, T. M., CONTI, R., COON, H., LAZENBY, J. and HERRON, M., 1996, Assessing the work environment for creativity. Academy of Management Journal, 39, pp. 1154-1184.

AMABILE, T.M.A., 1988, Model of creativity and innovation in organizations. In Research in Organizational Behavior, LLCBM Staw (Ed.), pp. 123-167 (Greenwich, CT: JAI Press).

ATKINSON, J.W., 1964, An Introduction to Motivation (New York: Van Nostrand).

BAGOZZI, R. P., DAVIS, F. D. and WARSHAW, P. R., 1992, Development and test of a theory of technological learning and usage. Human Relations, 45, pp. 659-686.

BANDURA, A.,1997, Self-Efficacy: The Exercise of Control (New York: Freeman).

BHATTACHERJEE, A., 2001, Understanding information systems continuance: An expectation-confirmation model. MIS Quarterly, 25, pp. 351-370.

BHATTACHERJEE, A. and PREMKUMAR, G., 2004, Understanding changes in belief and attitude toward information technology usage: A theoretical model and longitudinal test. MIS Quarterly, 28, pp. 229-254. 
BOMMER, M. and JAIAJAS, D.S., 1999, The threat of organizational downsizing on the innovative propensity of R\&D professionals. $R \& D$ Management, 29, pp. 27-34.

BOUDREAU, M.C., 2003, Learning to use ERP technology: A causal model. Proceedings of the 36th Hawaii International Conference on System Sciences.

BOUDREAU, M.C. and SELIGMAN, L., 2005, Quality of use of a complex technology: A learning-based model. Journal of Organizational and End Use Computing, 17, pp. 1-22.

BRISLIN, R.W., LONNER, W. and THORNDIKE, R.M., 1973, Cross-Culture Research Method (New York: Wiley).

CARLSON, J.R. and ZMUD, R.W., 1999, Channel expansion theory and the experiential nature of media richness perceptions. Academy of Management Journal, 42, pp. 153-170.

CHIN, W., 1998, Issues and opinion on structural equation modeling. MIS Quarterly, 22, vii-xvi.

CHIN, W. and MARCOLIN, B.L., 2001, The future of diffusion research. The DATA BASE for Advances in Information Systems, 32, pp. 8-12.

CHIN, W., MARCOLIN B.L. and NEWSTED, P.R., 2003, A partial least squares latent variable modeling approach for measuring interaction effects: Results from a Monte Carlo simulation study and an electronicmail emotion/adoption Study. Information Systems Research, 14, pp. 189-217.

CIBORRA, C.U., 1991, From thinking to tinkering: The grassroots of strategic information systems. Proceedings of International Conference on Information Systems, New York.

COMPEAU, D.R. and HIGGINS, C.A., 1995a, Application of social cognitive theory to training for computer skills. Information Systems Research, 6, pp. 118-140.

COMPEAU, D.R. and HIGGINS, C.A., 1995b, Computer self-efficacy: Development of a measure and initial test. MIS Quarterly, 19, pp. 189-211.

DAVIS, F.D., 1989, Perceived usefulness, perceived ease of use, and user acceptance of information technology. MIS Quarterly, 13, pp. 319-340.

DAVIS, F.D., BAGOZZI, R.P. and WARSHAW, P.R., 1989, User acceptance of computer technology: A comparison of two theoretical models. Management Science, 35, pp. 982-1003.

DESANCTIS, G. and POOLE, M. S., 1994, Capturing the complexity in advanced technology use: Adaptive 
structuration theory. Organization Science, 5, PP. 121-147.

DEVARAJ, S., EASLEY, R.F. and CRANT, J.M., 2008, How does personality matter? Relating the five-factor model to technology acceptance and use. Information Systems Research, 19, pp. 93-105.

EVANS, G.W., and LEPORE, S.J., 1997, Moderating and mediating processes in environment-behavior Research. In Advances in Environment, Behavior, and Design, G.T. Moore, and R.W. Marans (Eds.), pp. 250285 (New York: Plenum Press).

FORNELL, C. and LARCKER, D.F., 1981, Evaluating structural equation models with observable variables and measurement error. Journal of Marketing Research, 18, pp. 39-50.

GALLIVAN, M.J., SPILTER, V.K. and KOUFARIS, M., 2005, Does information technology training really matter? A social information processing analysis of coworkers' influence on IT usage in the workplace. Journal of Management Information Systems, 22, pp. 153-192.

GATTIKER, T.F. and GOODHUE, D.L., 2005, What happens after ERP implementation: Understanding the impact of inter-dependence and differentiation on plant-level outcomes. MIS Quarterly, 29, pp. 559-585.

GEFEN, D. and STRAUB, D., 2005, A practical guide to factorial validity and PLS-Graph: Tutorial and annotated example. Communication of the AIS, 16, pp. 91-109.

GOODHUE, D., LEWIS, W. and THOMPSON, R., 2007, Statistical power in analyzing interaction effects: Questioning the advantages of PLS with product indicators. Information Systems Research, 18, pp. 211-227.

HIRSCHMAN, E.C., 1980, Innovativeness, novelty seeking, and consumer creativity. Journal of Consumer Research, 7, pp. 283-295.

HSIEH, JJ., RAI, A. and KEIL, M., forthcoming, Addressing digital inequality for the socio-economically disadvantaged through government initiatives: Forms of capital that affect ICT utilization. Information Systems Research.

HSIEH, JJ. and WANT, W., 2007, Explaining employees' extended use of complex information systems. European Journal of Information Systems, 16, pp. 216-227.

HU, J., HUHMANN, B.A. and HYMAN, M.R., 2007, The relationship between task complexity and information search: The role of self-efficacy. Psychology \& Marketing, 24, pp. 253-270.

JASPERSON, J., CARTER, P.E. and ZMUD, R.W., 2005, A comprehensive conceptualization of post-adoptive 
behaviors associated with information technology enabled work systems. MIS Quarterly, 29, pp. 525-557.

KANARACUS, C., 2008, Gartner: Global IT Spending Growth Stable. Retrieved May 12, 2009, from http://www.infoworld.com/t/business/gartner-global-it-spending-growth-stable-523.

KARAHANNA, E. and AGARWAL, R., 2006, When the spirit is willing: Symbolic adoption and technology exploration. University of Georgia, Athens, GA.

KIM, S.S. and MALHOTRA, N.K., 2005, Predicting system usage from intention and past use: Scale issues in the predictors. Decision Science, 36, pp. 187-196.

KRUEGER, N.J. and DICKSON, P.R., 1993, Perceived self-efficacy and perceptions of opportunity and threat. Psychological Reports, 72, pp. 1235-1240.

KRUEGER, N.J. and DICKSON, P.R., 1994, How believing in ourselves increase risk taking: Perceived selfefficacy and opportunity recognition. Decision Science, 25, pp. 385-400.

LATHAM, G.P., LOCKE, E.A., and FASSINA, N.E., 2000, The high performance cycle: Standing the test of time. In The Psychological Management of Individual Performance. A Handbook in the Psychology of Management in Organizations, S. Sonnentag (Ed.), pp. 201-228 (Chichester: Wiley).

LEWIS, W., AGARWAL, R. and SAMBAMURTHY, V., 2003, Sources of influence on beliefs about information technology use: An empirical study of knowledge workers. MIS Quarterly, 27, pp. 657-678.

LI, X. and HSIEH, J.P., 2007, Impact of transformational leadership on system exploration in the mandatory organizational context. Proceedings of 28th International Conference on Information Systems. Canada: Montreal.

LI, Y., TAN, C.H., TEO, H.H. and TAN, B.C.Y., 2006, Innovative usage of information technology in Singapore organizations: Do CIO characteristics make a difference? IEEE Transactions on Engineering Management, 53, pp. 177-190.

LIANG, H., SARAF, N., HU, Q. and XUE, Y., 2007, Assimilation of enterprise systems: The effect of institutional pressures and the mediating role of top management. MIS Quarterly, 31, pp. 59-87.

LUTHANS, F. and YOUSSEF, C.M., 2007, Emerging positive organizational behavior. Journal of Management, 33, pp. 321-349.

MACKINNON, D. W., 1962, The nature and nurture of creative talent. American Psychologist, 17, pp. 484-495. 
MARTOCCHIO, J.J. and DULEBOHN, J.S., 1994, Performance feedback effects in training: The role of perceived controllability. Personnel Psychology, 47, pp. 357-373.

MARTOCCHIO, J.J. and WEBSTER, J., 1992, Effects of feedback and cognitive playfulness on performance in microcomputer software training. Personnel Psychology, 45, pp. 553-578.

MILLS, A. and CHIN, W., 2007, Conceptualizing creative use: An examination of the construct and its determinants. Proceedings of the Americas Conference on Information Systems (AMCIS), USA: Colorado.

MOORE, J.B.I., 2002, Information Technology Infusion: A Motivation Approach. Department of Information and Management Sciences, The Florida State University.

NAH F.F.H., TAN X. and TEH S.H., 2004, An empirical investigation on end-users' acceptance of enterprise systems. Information Resources Management Journal, 17, pp. 32-53.

NAMBISAN, S., AGARWAL, R. and TANNIRU, M., 1999, Organizational mechanisms for enhancing user innovation in information technology. MIS Quarterly, 23, pp. 365-395.

NEGASH, S. and GRAY, P., 2008, International handbooks on information systems. In Handbook on Decision Support Systems 2: Variations, B. Frada ans C.W. Holsapple (Eds.), pp. 175-194 (Springer Berlin Heidelberg). NUNNALLY, J.C., 1994, Psychometric theory, 3rd Ed.(New York: McGraw-Hill).

OLIVER, R.L., 1980, A cognitive model of the antecedents and consequences of satisfaction decisions. Journal of Marketing Research, 17, pp. 460-469.

OLIVER, T. A. and SHAPIRO, F., 1993, Self-efficacy and computers. Journal of Computer-Based Interactions, 20, pp. 81-85.

PODSAKOFF, P.M., MACKENZIE, S.B., LEE, J.Y. and PODSAKOFF, N.P., 2003, Common method biases in behavioral research: A critical review of the literature and recommended remedies. Journal of Applied Psychology, 88, pp. 879-903.

PODSAKOFF, P.M. and ORGAN, D.W., 1986, Self-reports in organizational research: Problems and prospects. Journal of Management, 12, pp. 531-544.

PORTER, S.M. and LAWLER, E.E., 1968, Managerial Attitudes and Performance (Homewood, IL: Irwin).

POZZEBON, M., 2002, Combining a Structuration Approach with a Behavioral-based Model to Investigate 
ERP Usage. Americas Conference on Information Systems, Long Beach, CA.

RINGLE, C.M., WENDE, S. and WILL A., 2005, University of Hamburg, Hamburg, Germany. http://www.smartpls.de

ROGERS, E.M., 2003, Diffusion of innovation (New York: Free Press).

SAGA, V.L. and ZMUD, R.W., 1994. The nature and determinants of IT acceptance, routinization, and infusion. In Diffusion, transfer and implementation of information technology, L. Levine (Ed.), pp. $67-86$ (Amsterdam: North-Holland).

SCHAEFERS, K.G., EPPEERSON, D.L. and NAUTA, M.M., 1997, Women's career development: Can theoretically derived variables predict persistence in engineering majors? Journal of Counseling Psychology, 44, pp. 173-183.

STERNBERG, R.J., O’HARA, L.A. and LUBART, T.I., 1997, Creativity as investment. California Management Review, 40, pp. 8-21.

SUN, H. and ZHANG, P., 2006, The role of moderating factors in user technology acceptance. International Journal of Human-Computer Studies, 64, pp. 53-78.

SUN, H. and ZHANG, P., 2008, Adaptive system use: An investigation at the system feature level. Proceedings of the International Conference on Information Systems, Paris.

TAYLOR, S. and TODD, P.A., 1995, Understanding information technology usage: A test of competing models. Information Systems Research, 6, pp. 144-176.

THATCHER, J.B. and PERREWE, P.L., 2002, An empirical examination of individual traits as antecedents to computer anxiety and computer self-efficacy. MIS Quarterly, 26, pp. 381-396.

Van Der HEIJDEN H., 2004, User acceptance of hedonic information systems. MIS Quarterly, 28, pp. 695-704.

VANYEPERTEN, N.W., 1998, Informational support, equity and burnout: The moderating effect of selfefficacy. Journal of Occupational and Organizational Psychology, 71, pp. 29-33.

VENKATESH, V., MORRIS, M.G., DAVIS, G.B. and DAVIS, F.D., 2003, User acceptance of information technology: Toward a unified view. MIS Quarterly, 27, pp. 425-478.

WANG, W. and HSIEH, J.J., 2006, Symbolic adoption, extended use, and emergent use of complex information systems in the mandatory organizational context. Proceedings of 27 th International Conference on 
Information Systems, Milwaukee.

WESTLAND, J.C. and CLARK, T.H.K., 2000, Global Electronic Commerce: Theory and Case Studies (Cambridge, MA: MIT Press).

WOHLWILL, J. and HEFT, H., 1987, The physical environment and the development of the child. In Handbook of Environmental Psychology, D. Stokols and I. Altman (Eds.), pp. 281-328 (New York: Wiley).

WOOD, R.E., ALLEN, J., PILlingER, T. and KOHN, N., 1999, 360 degree feedback: Theory, research and practice. In Human Resource Strategies: An Applied Approach, A.V.M. Travaglione (Ed.), pp. 209-228 (Sydney: Irwin/ McGraw-Hill).

YI, M.Y., JACKSON, J.D., PARK, J.S. and PROBST, J.C., 2006, Understanding information technology acceptance by individual professionals: Toward an integrative view. Information \& Management, 43, pp. 350363. 
TABLE 1. Sample demographics (Study 1).

\begin{tabular}{|c|c|c|}
\hline \multirow{2}{*}{ Category } & Percentage (\%) \\
\hline \multirow{4}{*}{ Education } & Senior High School or Below & 24.0 \\
\cline { 2 - 3 } & College & 33.0 \\
\cline { 2 - 3 } & Bachelor's Degree & 40.0 \\
\cline { 2 - 3 } & Master's or Above & 3.0 \\
\cline { 2 - 3 } & Total & 100 \\
\hline \multirow{4}{*}{ Age } & $18-29$ & 37.0 \\
\cline { 2 - 3 } & $30-39$ & 47.0 \\
\cline { 2 - 3 } & 41 or Above & 16.0 \\
\cline { 2 - 3 } Gender & Total & 100 \\
\cline { 2 - 3 } & Female & 46.0 \\
\cline { 2 - 3 } & Male & 54.0 \\
\cline { 2 - 3 } & Total & 100 \\
\hline
\end{tabular}

TABLE 2. Sample demographics (Study 2).

\begin{tabular}{|c|c|c|}
\hline \multirow{2}{*}{ Category } & Percentage (\%) \\
\hline \multirow{4}{*}{ Education } & Senior High School or Below & 2.6 \\
\cline { 2 - 3 } & College & 17.6 \\
\cline { 2 - 3 } & Bachelor's Degree & 67.9 \\
\cline { 2 - 3 } & Master's or Above & 11.9 \\
\cline { 2 - 3 } & Total & 100 \\
\hline \multirow{4}{*}{ Age } & $18-29$ & 54.4 \\
\cline { 2 - 3 } & $30-39$ & 38.9 \\
\cline { 2 - 3 } & 41 or Above & 6.7 \\
\cline { 2 - 3 } & Total & 100 \\
\cline { 2 - 3 } Gender & Female & 37.3 \\
\cline { 2 - 3 } & Male & 62.7 \\
\cline { 2 - 3 } & Total & 100 \\
\cline { 2 - 3 } & & \\
\hline
\end{tabular}

TABLE 3. Descriptive statistics, internal consistency, and discriminant validity (study 1).

\begin{tabular}{|c|c|c|c|c|c|c|c|}
\hline Variable & Mean & S.D. & PU & SAT & PIIT & ITSE & IwIT \\
\hline PU & 5.43 & 1.07 & 0.72 & & & & \\
\hline SAT & 4.81 & 1.36 & 0.42 & 0.92 & & & \\
\hline PIIT & 4.96 & 1.15 & 0.07 & 0.05 & 0.69 & & \\
\hline ITSE & 5.16 & 1.16 & 0.03 & 0.01 & 0.12 & 0.80 & \\
\hline IwIT & 4.69 & 1.26 & 0.22 & 0.16 & 0.08 & 0.01 & 0.90 \\
\hline \multicolumn{3}{|c|}{ Cronbach's Alpha } & 0.81 & 0.95 & 0.74 & 0.88 & 0.88 \\
\hline \multicolumn{3}{|c|}{ Composite Reliability } & 0.88 & 0.97 & 0.76 & 0.92 & 0.94 \\
\hline
\end{tabular}


TABLE 4. Item loading and cross loadings (study 1).

\begin{tabular}{|c|c|c|c|c|c|}
\hline Item & PU & SAT & PIIT & ITSE & IwIT \\
\hline PU1 & 0.77 & 0.56 & 0.17 & 0.24 & 0.27 \\
PU2 & 0.87 & 0.53 & 0.24 & 0.07 & 0.39 \\
PU3 & 0.89 & 0.52 & 0.26 & 0.13 & 0.49 \\
\hline SAT1 & 0.53 & 0.96 & 0.22 & 0.09 & 0.43 \\
SAT2 & 0.51 & 0.94 & 0.20 & 0.13 & 0.31 \\
SAT3 & 0.53 & 0.97 & 0.24 & 0.13 & 0.40 \\
\hline PIIT1 & 0.30 & 0.26 & 0.93 & 0.32 & 0.31 \\
PIIT2 & 0.06 & 0.10 & 0.77 & 0.26 & 0.17 \\
PIIT3 & 0.30 & 0.15 & 0.78 & 0.27 & 0.10 \\
\hline ISSE1 & 0.17 & 0.17 & 0.30 & 0.85 & 0.08 \\
ISSE2 & 0.11 & 0.09 & 0.33 & 0.89 & 0.10 \\
ISSE3 & 0.15 & 0.08 & 0.32 & 0.95 & 0.13 \\
\hline IwIT1 & 0.42 & 0.34 & 0.26 & 0.07 & 0.94 \\
IwIT2 & 0.47 & 0.42 & 0.27 & 0.14 & 0.95 \\
\hline
\end{tabular}

TABLE 5. Descriptive statistics, internal consistency, and discriminant validity (study 2).

\begin{tabular}{|c|c|c|c|c|c|c|c|}
\hline Variable & Mean & S.D. & $\mathbf{P U}$ & SAT & PIIT & ITSE & IwIT \\
\hline PU & 5.32 & 0.91 & 0.85 & & & & \\
\hline SAT & 5.15 & 1.04 & 0.28 & 0.85 & & & \\
\hline PIIT & 5.41 & 0.89 & 0.13 & 0.04 & 0.78 & & \\
\hline ITSE & 4.98 & 0.96 & 0.19 & 0.21 & 0.10 & 0.69 & \\
\hline IwIT & 4.90 & 1.03 & 0.19 & 0.15 & 0.10 & 0.14 & 0.86 \\
\hline \multicolumn{3}{|c|}{ Cronbach's Alpha } & 0.91 & 0.91 & 0.86 & 0.76 & 0.86 \\
\hline \multicolumn{3}{|c|}{ Composite Reliability } & 0.94 & 0.94 & 0.92 & 0.86 & 0.94 \\
\hline
\end{tabular}

TABLE 6. Item loadings and cross loadings (study 2).

\begin{tabular}{|c|c|c|c|c|c|}
\hline Item & PU & SAT & PIIT & ITSE & IwIT \\
\hline PU1 & 0.92 & 0.46 & 0.30 & 0.41 & 0.38 \\
PU2 & 0.94 & 0.52 & 0.36 & 0.46 & 0.43 \\
PU3 & 0.91 & 0.46 & 0.32 & 0.43 & 0.39 \\
\hline SAT1 & 0.47 & 0.90 & 0.16 & 0.46 & 0.33 \\
SAT2 & 0.52 & 0.96 & 0.21 & 0.46 & 0.39 \\
SAT3 & 0.46 & 0.91 & 0.19 & 0.37 & 0.37 \\
\hline PIIT1 & 0.36 & 0.18 & 0.88 & 0.35 & 0.27 \\
PIIT2 & 0.30 & 0.23 & 0.90 & 0.30 & 0.30 \\
PIIT3 & 0.30 & 0.13 & 0.87 & 0.25 & 0.25 \\
\hline ISSE1 & 0.54 & 0.48 & 0.38 & 0.91 & 0.35 \\
ISSE2 & 0.46 & 0.46 & 0.32 & 0.92 & 0.32 \\
ISSE3 & 0.10 & 0.20 & 0.12 & 0.83 & 0.24 \\
\hline IwIT1 & 0.46 & 0.38 & 0.28 & 0.34 & 0.94 \\
IwIT2 & 0.36 & 0.36 & 0.30 & 0.36 & 0.94 \\
\hline
\end{tabular}


TABLE 7. Results of PLS analysis (study 1).

\begin{tabular}{|c|c|c|c|c|}
\hline & & & nt Variabl & \\
\hline Var & ables & Model 1 & Model 2 & Model 3 \\
\hline & Tenure & -0.076 & -0.095 & -0.074 \\
\hline & Education & $-0.205^{* *}$ & $-0.185^{* *}$ & $-0.179 * *$ \\
\hline Control & Age & -0.122 & -0.028 & -0.033 \\
\hline & Gender & -0.043 & -0.012 & -0.011 \\
\hline & Use Time & $0.130 *$ & $0.140 *$ & $0.136^{*}$ \\
\hline & PU & & $0.320^{* *}$ & $0.298 * *$ \\
\hline Direct & SAT & & $0.162 *$ & $0.190 *$ \\
\hline Effect & ITSE & & -0.024 & -0.016 \\
\hline & PIIT & & $0.162^{* *}$ & $0.157 *$ \\
\hline & PU * PIIT & & & -0.113 \\
\hline Interaction & SAT $*$ PIIT & & & $0.204^{* *}$ \\
\hline Effect & $\mathrm{PU} *$ ITSE & & & $0.230 * *$ \\
\hline & SAT * ITSE & & & $-0.209^{* *}$ \\
\hline & & $6.1 \%$ & $30.8 \%$ & $36.5 \%$ \\
\hline & & & $24.7 \%$ & $5.7 \%$ \\
\hline$+\mathrm{p}<0.1$ & $p<0.05$ & & & \\
\hline
\end{tabular}

TABLE 8. Results of PLS analysis (study 2).

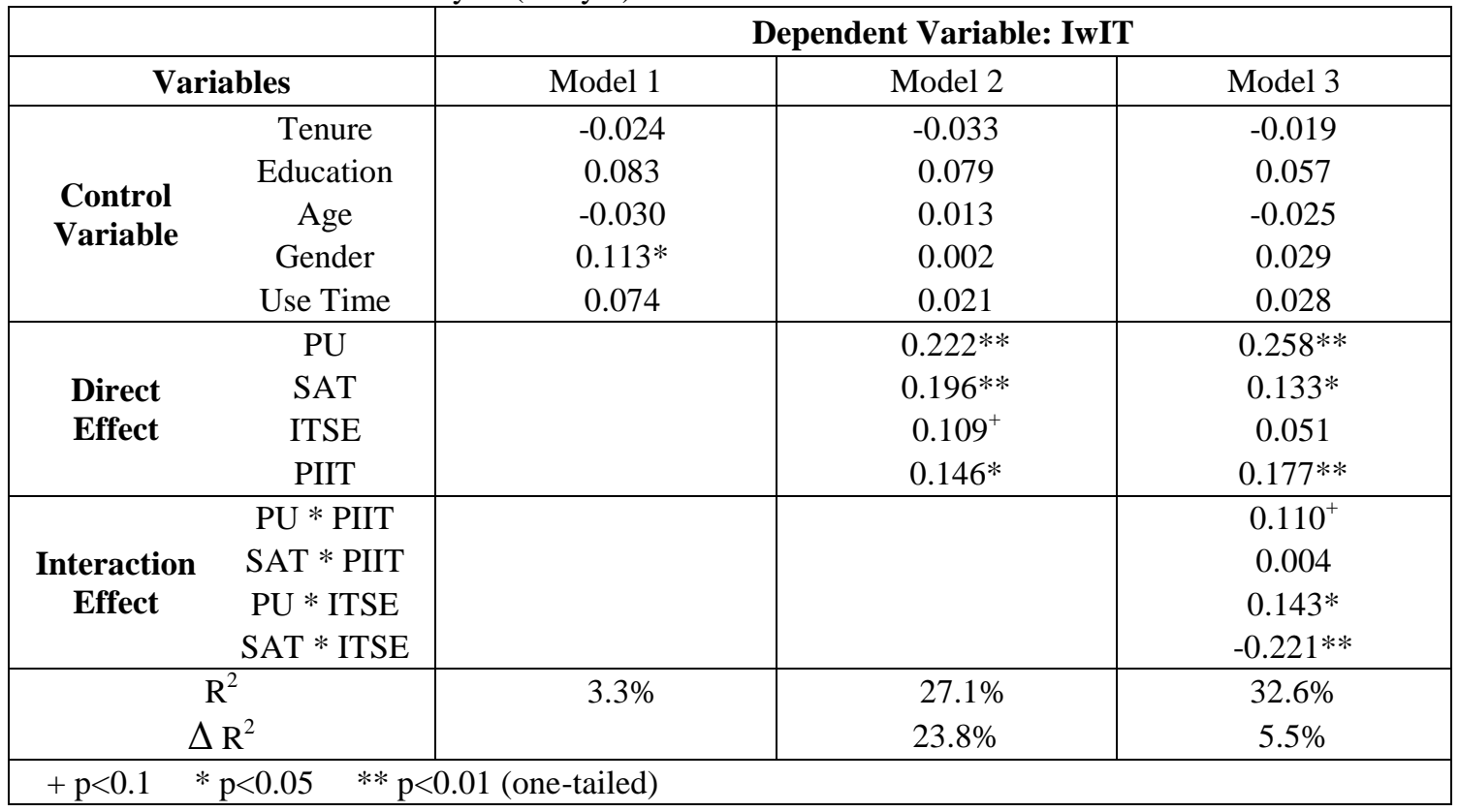


TABLE 9. Summary of findings.

\begin{tabular}{|c|c|c|c|c|c|}
\hline \multirow{2}{*}{\multicolumn{2}{|c|}{ Models/Factors }} & \multirow[b]{3}{*}{ H1 (PU $\rightarrow$ IwIT) } & \multicolumn{2}{|c|}{ Results } & \multirow[b]{2}{*}{ Findings } \\
\hline & & & \multirow{2}{*}{$\begin{array}{c}\begin{array}{c}\text { ERP } \\
\text { technology }\end{array} \\
\sqrt{ }\end{array}$} & $\begin{array}{c}\text { BI } \\
\text { technology }\end{array}$ & \\
\hline \multirow{2}{*}{$\begin{array}{l}\text { IS } \\
\text { Continuance } \\
\text { Model }\end{array}$} & PU & & & $\sqrt{ }$ & \multirow{2}{*}{$\begin{array}{l}\text { Fully supported: } \\
\text { IS continuance model successfully } \\
\text { explained IwIT as a continuance usage } \\
\text { behavior at the post-acceptance stage. }\end{array}$} \\
\hline & SAT & $\mathrm{H} 2(\mathrm{SAT} \rightarrow \mathrm{IwIT})$ & $\sqrt{ }$ & $\sqrt{ }$ & \\
\hline \multirow{4}{*}{$\begin{array}{c}\text { Individual } \\
\text { Characteristics } \\
\text { as Boundary } \\
\text { Conditions }\end{array}$} & \multirow[b]{2}{*}{ PIIT } & H3a (moderate PU $\rightarrow$ IwIT) & $x$ & $\sqrt{ }$ & \multirow{2}{*}{$\begin{array}{l}\text { Partially supported: } \\
\text { PIIT positively moderated the impact of } \\
\text { PU on IwIT in the context of ERP } \\
\text { technology and positively moderated } \\
\text { the impact of SAT on IwIT in the } \\
\text { context of BI technology. }\end{array}$} \\
\hline & & H3b (moderate SAT $\rightarrow$ IwIT) & $\sqrt{ }$ & $x$ & \\
\hline & \multirow{2}{*}{ ISE } & H4a (moderate PU $\rightarrow$ IwIT) & $\sqrt{ }$ & $\sqrt{ }$ & \multirow{2}{*}{$\begin{array}{l}\text { Fully Supported: } \\
\text { ITSE positively moderated the impact } \\
\text { of PU on IwIT, while it negatively } \\
\text { moderated the impact of SAT on IwIT. }\end{array}$} \\
\hline & & H4b (moderate SAT $\rightarrow$ IwIT) & $\sqrt{ }$ & $\sqrt{ }$ & \\
\hline
\end{tabular}




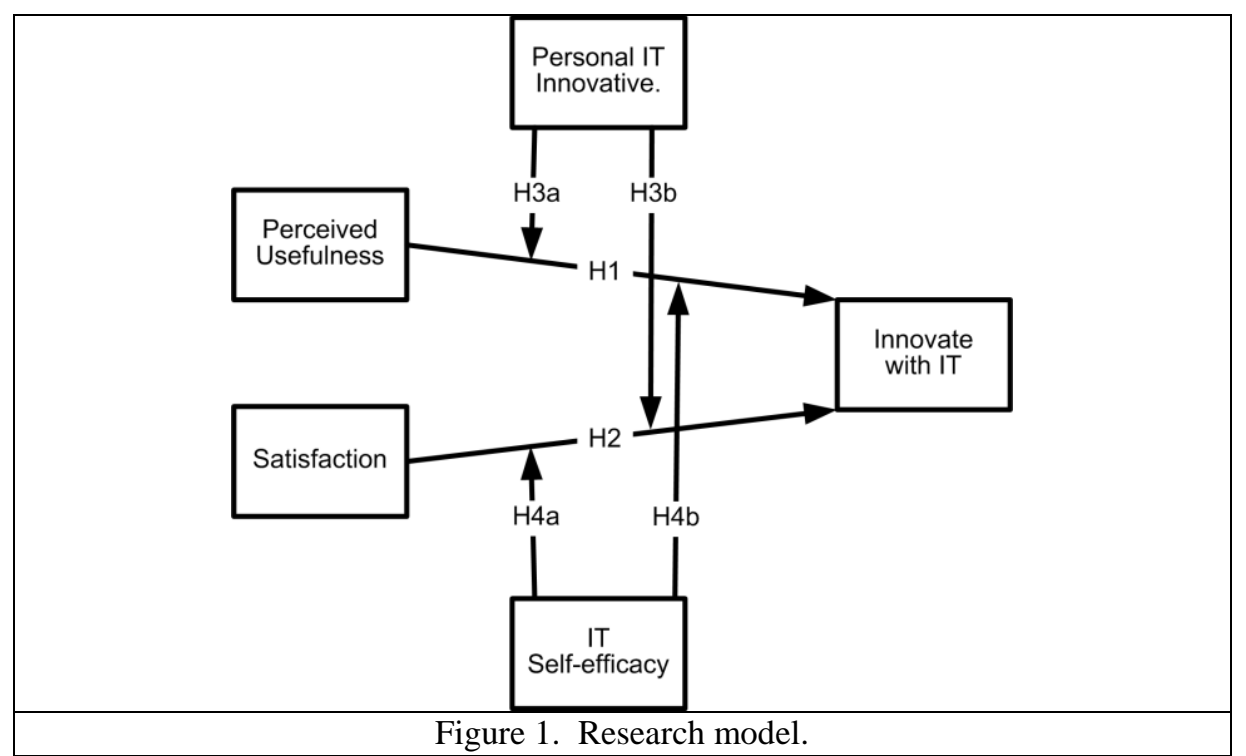

Page 38 of 39 


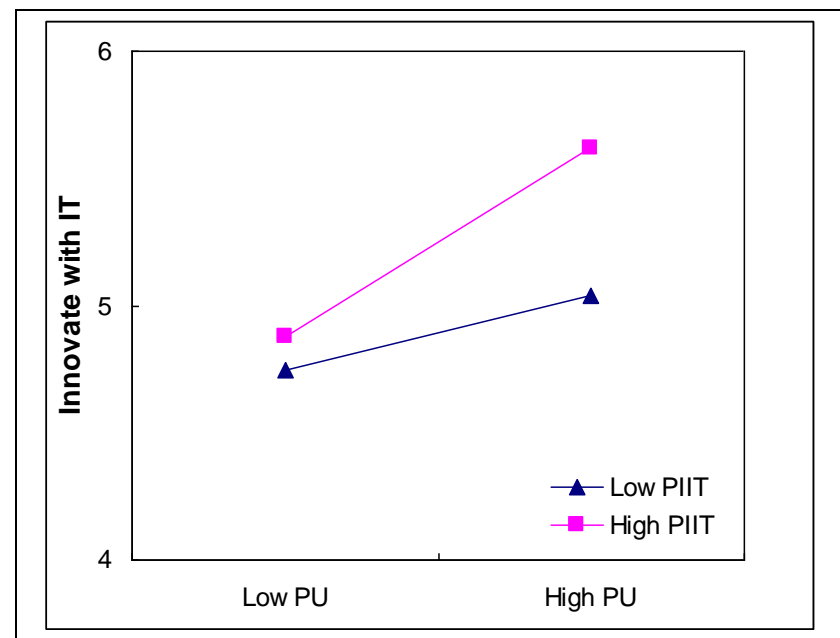

Figure 2. H3a (PU versus PIIT in study 2).

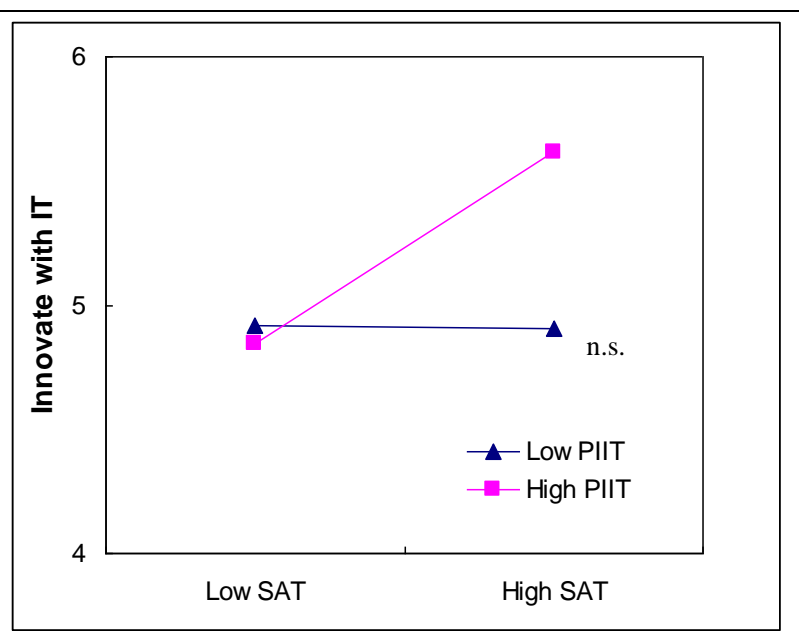

Figure 3. H3b (SAT versus PIIT in study 1).

n.s.: none significant path, i.e., the path coefficient is not significantly different from zero

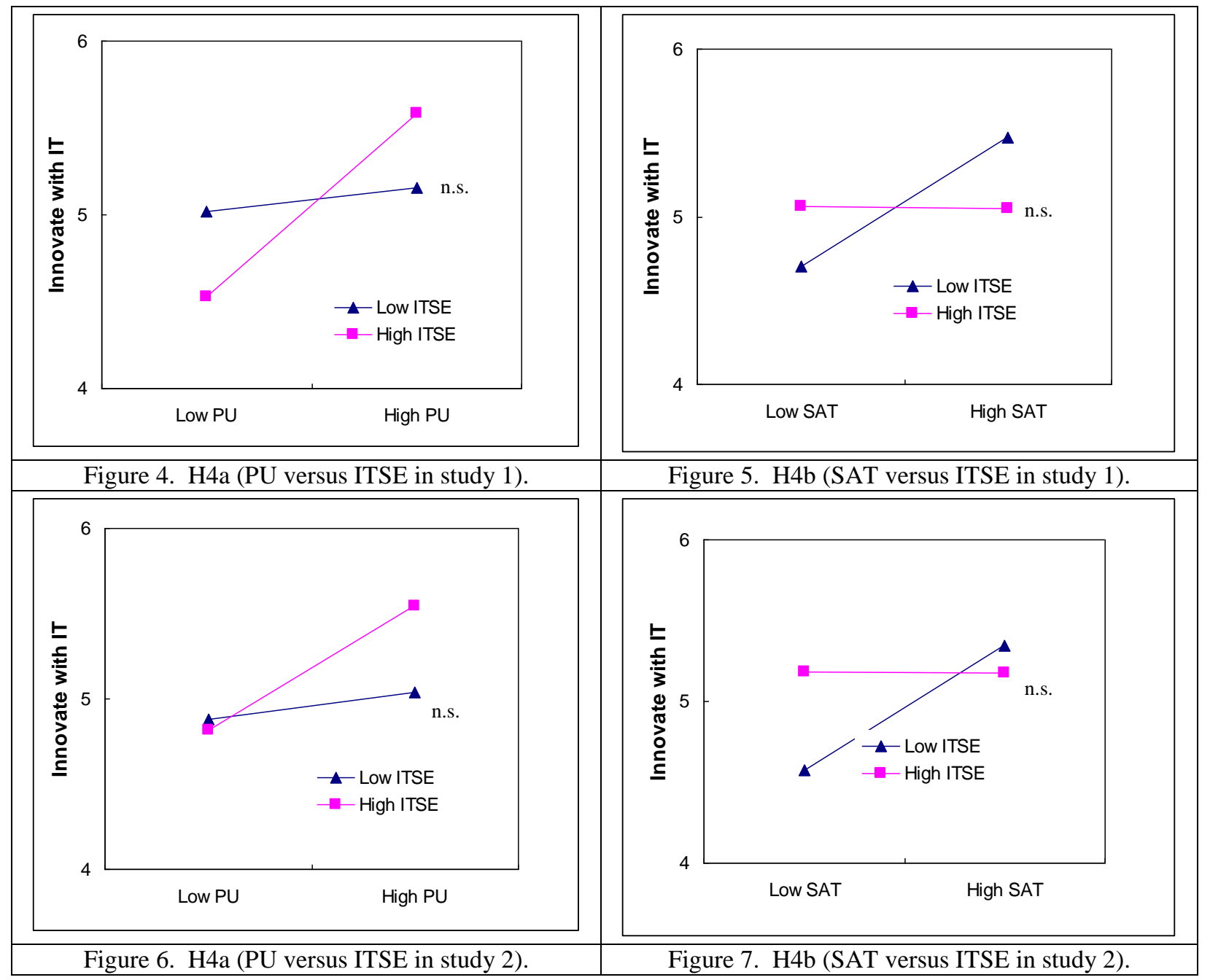

n.s.: none significant path, i.e., the path coefficient is not significantly different from zero 